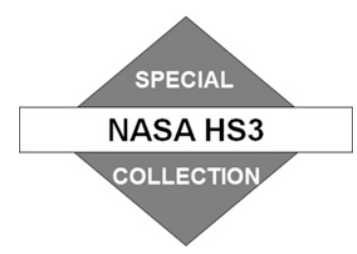

\title{
Microphysics and Radiation Effect of Dust on Saharan Air Layer: An HS3 Case Study
}

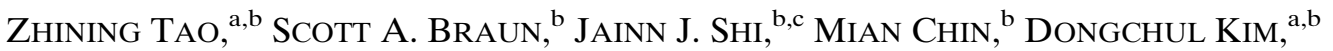 \\ TOSHIHISA MATSUi, ${ }^{\mathrm{b}, \mathrm{d}}$ AND CHRISTA D. PETERS-LIDARD ${ }^{\mathrm{b}}$ \\ ${ }^{a}$ Universities Space Research Association, Columbia, Maryland \\ ${ }^{\mathrm{b}}$ NASA Goddard Space Flight Center, Greenbelt, Maryland \\ ${ }^{\mathrm{c}}$ Morgan State University, Baltimore, Maryland \\ ${ }^{\mathrm{d}}$ Earth System Science Interdisciplinary Center, University of Maryland, College Park, College Park, Maryland
}

(Manuscript received 28 September 2017, in final form 23 February 2018)

\begin{abstract}
A Saharan air layer (SAL) event associated with a nondeveloping African easterly wave (AEW) over the main development region of the eastern Atlantic was sampled by the NASA Global Hawk aircraft on 24-25 August 2013 during the NASA Hurricane and Severe Storm Sentinel (HS3) campaign and was simulated with the NASA Unified Weather Research and Forecasting (NU-WRF) Model. Airborne, ground-based, and spaceborne measurements were used to evaluate the model performance. The microphysical and radiative effects of dust and other aerosols on the SAL structure and environment were investigated with the factor-separation method. The results indicate that relative to a simulation without dust-radiative and microphysical impacts, Saharan dust and other aerosols heated the SAL air mainly through shortwave heating by the direct aerosol-radiation (AR) effect, resulting in a warmer (up to $0.6 \mathrm{~K}$ ) and drier (up to $5 \%$ RH reduction) SAL and maintaining the strong temperature inversion at the base of the SAL in the presence of predominant longwave cooling. Radiative heating of the dust accentuated a vertical circulation within the dust layer, in which air rose (sank) in the northern (southern) portions of the dust layer. Furthermore, above and to the south of the dust layer, both the microphysical and radiative impacts of dust tended to counter the vertical motions associated with the Hadley circulation, causing a small weakening and southward shift of convection in the intertropical convergence zone (ITCZ) and reduced anvil cloud to the north. Changes in moisture and cloud/precipitation hydrometeors were largely driven by the dustinduced changes in vertical motion. Dust strengthened the African easterly jet by up to $\sim 1 \mathrm{~m} \mathrm{~s}^{-1}$ at the southern edge of the jet, primarily through the AR effect, and produced modest increases in vertical wind shear within and in the vicinity of the dust layer. These modulations of the SAL and AEW environment clearly contributed to the nondevelopment of this AEW.
\end{abstract}

\section{Introduction}

The Saharan air layer (SAL) is formed by strong sensible heating of the westward-moving air over the arid Sahara Desert (Prospero et al. 1970; Prospero and Carlson 1970, 1972; Carlson and Prospero 1972; Karyampudi and Carlson 1988), and its structure and evolution have been characterized in detail through a number of observational studies using satellite-, ship-, and aircraft-based measurements (e.g., Carlson 1979; Karyampudi and Carlson 1988; Karyampudi et al. 1999; Dunion and Velden 2004; Nalli et al. 2005; Parker et al. 2005; Messager et al. 2010; Ismail et al. 2010; Braun 2010). The SAL resides above a wellmixed marine boundary layer capped by the trade wind inversion at approximately $850 \mathrm{hPa}$. It generally extends

Corresponding author: Dr. Zhining Tao, zhining.tao@nasa.gov up to $500 \mathrm{hPa}$ near the West African coast, but the base rises and the top descends to the west across the Atlantic Ocean (Karyampudi and Carlson 1988; Parker et al. 2005; Braun 2010). The air within the SAL is warm and dry at low levels but tends to be cooler than the surrounding tropical atmosphere at the SAL top, leading to another temperature inversion to cap the SAL (Carlson and Prospero 1972; Karyampudi and Carlson 1988; Braun 2010). Using sun photometer and radiosonde data collected from the NOAA ship Ronald H. Brown during the Aerosol and Ocean Science Expedition (AEROSE) in March 2004, Nalli et al. (2005) analyzed the SAL vertical structure. They showed that the SAL was much drier than the Jordan July-October sounding. By analyzing the wind and virtual potential temperature, Nalli et al. (2005) indicated a vast warm, dry, and turbid stable air column above the marine boundary layer. Dunion and 
Marron (2008) and Dunion (2011) also characterized the thermodynamic properties of the SAL relative to the Jordan mean sounding and showed results similar to Nalli et al. (2005).

The SAL has a sharp horizontal temperature gradient along its western and southern edges (Karyampudi and Carlson 1988; Braun 2010), similar to a front, with 3-4 K of temperature difference across distances of $\sim 30-150 \mathrm{~km}$ (Carlson and Prospero 1972). Thermal wind balance results in the midlevel African easterly jet (AEJ; Carlson and Prospero 1972; Karyampudi and Carlson 1988; Cook 1999; Thorncroft and Hoskins 1994; Chen et al. 2015). The AEJ results in enhanced vertical wind shear, increased vorticity south of the jet, and an ageostrophic transverse circulation with enhanced upward motion to the south of the jet, but downward motion within the SAL (Karyampudi and Carlson 1988). The AEJ near the leading edge of the low-level dry SAL was also observed during the AEROSE campaign (Nalli et al. 2005).

SAL outbreaks are often accompanied by elevated dust loading, mainly caused by African easterly wave (AEW) disturbances in the Saharan heat low region (Barkan et al. 2004; Ben-Ami et al. 2009). The Saharan heat low leads to strong surface pressure gradients and converging low-level flow that lifts dust up to the $\sim 500-\mathrm{hPa}$ level. This dust layer is transported westward in the SAL along with the AEW, generally above the humid trade wind air of the marine boundary layer just off the coast of western Africa. A dust concentration of 2-4 g kg ${ }^{-1}$ is common in the SAL (Carlson and Prospero 1972). As a strong shortwave absorbing aerosol, dust is able to impact the radiative balance and modify the vertical heating profile within the SAL and its surrounding atmosphere. Using a radiative transfer model, Carlson and Benjamin (1980) reported a $1 \mathrm{~K}$ day $^{-1}$ warming averaged between 1000 and $500 \mathrm{hPa}$ (including the air within and below the SAL) over the ocean due to dust. Karyampudi and Carlson (1988) claimed that radiative heating by dust was responsible for maintaining a warmer and deeper SAL over the ocean and enhancing the AEJ strength. Chen et al. (2010) examined the dustradiation effect on the SAL over the eastern Atlantic using a regional model with interactive dust for a dust outbreak event during 18-20 July 2005. They found that dust enhanced the shortwave heating around the dust maximum in the dust layer and produced cooling below the dust layer. On the other hand, dust caused longwave cooling of the dust layer and warming at the surface. The net effect was to warm both the dust layer and surface. They further concluded that below $700 \mathrm{hPa}$, radiative heating of dust increased atmospheric stability as a result of the increased temperature and dryness. In contrast, Ma et al. (2012) found low-level warming/ midlevel cooling associated with a prescribed dust layer, resulting in decreased stability. In a separate study, Chen et al. (2015) suggested that the energy budget change induced by the dust-radiation interaction could lead to changes in the horizontal temperature gradient near the southern edge of the SAL, which could alter the intensity of the AEJ and the vertical wind shear through thermal wind balance.

Recent measurements also show that Saharan dust can serve as cloud condensation nuclei $(\mathrm{CCN}$; Twohy et al. 2009) and ice nuclei (IN; Twohy 2015) over the eastern Atlantic Ocean. Whether aerosols serving as $\mathrm{CCN}$ and IN can enhance or reduce local cloud and precipitation depends on the regional environment (Tao et al. 2007; Khain et al. 2008). Rosenfeld et al. (2008, and references therein) summarized that added $\mathrm{CCN}$ would increase the number of cloud drops but slow the raindrop coalescence process. This effect tends to shut off precipitation from shallow clouds but invigorate deep convective rain clouds with warm cloud bases. Shi et al. (2014) investigated the impacts of the aerosol indirect and direct effects on the mesoscale convective system (MCS) over the West Africa region and found that the dust aerosol indirect effect was overwhelmed by their direct effect, which delayed the onset of the MCS. Based on an observational investigation of a trans-Atlantic Saharan dust outbreak event in March 2004, Min et al. (2009) concluded that the microphysical impact of dust aerosols was to suppress precipitation.

The Hurricane and Severe Storm Sentinel (HS3) investigation, funded under NASA's Earth Venture Suborbital program, was geared toward a better understanding of the physical processes that controlled hurricane intensification (Braun et al. 2016). Although the primary project goals were to investigate the mechanisms involved in, and to improve the predictability of, hurricane intensity change, HS3 had secondary goals to examine SAL thermodynamic, kinematic, and dust structures in relation to AEW structure and potential tropical storm development. Specifically, how does Saharan dust modify SAL, AEJ, and AEW structures, and do those changes make conditions more or less favorable for storm development? Karyampudi and Carlson (1988) suggested that the SAL might enhance rising motions in the intertropical convergence zone (ITCZ), thus favoring tropical cyclogenesis, but that with increased dust loading, this effect might be countered by vertical circulations induced by radiative heating of the dust. What are the distribution and magnitude of the dust-induced vertical circulation and their impacts on the SAL and its environment? Given that temperature changes caused by dust heating may 
enhance vertical wind shear associated with the AEJ (Chen et al. 2015), do these changes in vertical shear make environmental conditions more unfavorable for genesis?

To examine these SAL-related issues, HS3 deployed a Global Hawk uninhabited aircraft system (UAS) to collect data during an SAL outbreak associated with a nondeveloping AEW on 24-25 August 2013. The Global Hawk was equipped with the NASA Cloud Physics lidar (CPL), the Airborne Vertical Atmospheric Profiling System (AVAPS; referred to as dropsonde hereafter; Hock and Franklin 1999), and the University of Wisconsin-Madison Space Science and Engineering Center Scanning High-Resolution Interferometer Sounder (S-HIS).

This study also uses the NASA Unified Weather Research and Forecasting (NU-WRF) modeling system (Peters-Lidard et al. 2015; Tao et al. 2016) to investigate the 24-25 August SAL outbreak. The radiative and microphysical effects of dust and other aerosols on the SAL structure are analyzed. The paper is organized as follows: section 2 provides a brief description of the observational data and model used in this study, section 3 describes briefly the SAL event, section 4 describes the model configuration and experiment setup, and section 5 summarizes the analysis of the observations and simulations. Conclusions are provided in section 6 .

\section{Data and NU-WRF}

Data from CPL and dropsondes collected during the HS3 campaign are utilized for this study. CPL is a multiwavelength backscatter lidar that measures the optical and radiative properties of cirrus clouds and aerosols (McGill and Hlavka 2015). The AVAPS system carries up to 88 dropsondes that provide high vertical resolution (2-Hz sampling) profiles of temperature, pressure, humidity, wind speed, and wind direction (Wick 2015; Braun et al. 2016) from just below flight level $(\sim 18 \mathrm{~km})$ to the surface.

Aerosol optical depth (AOD) data measured by the Moderate Resolution Imaging Spectroradiometer (MODIS) on board Terra and Aqua satellites are used for event description and model comparisons. MODIS provides global coverage of AOD at midvisible wavelength over land and ocean (e.g., Remer et al. 2005; Levy et al. 2013). Figure 1 shows daytime snapshots of data from Collection 6 products utilizing the dark target algorithm (Kaufman et al. 1997) that retrieves AOD over ocean and "dark" land.

AOD data measured by sun photometers from the Aerosol Robotic Network (AERONET; Holben et al. 1998) are also used for model performance evaluation.
AERONET is a ground-based network for remote sensing of aerosol optical, microphysical, and radiative properties. It imposes standardized instruments, calibration, processing, and distribution across the network. The quality-assured level 2 data have been used in this investigation.

The NU-WRF Model is used to simulate this SAL event and to investigate the role of dust and other aerosols in the local atmospheric structure. NU-WRF is a regional Earth system modeling system coupled with the WRF-Chem Model (version 3.5.1) that represents atmospheric chemistry, aerosol, cloud, precipitation, and land processes at convection-permitting spatial scales (typically $1-6 \mathrm{~km}$ ). In this way, NU-WRF can be applied for fully coupled aerosol-microphysics-radiation interaction simulations. The detailed model structure, chemistry/aerosol representation, and applications can be found in Tao et al. (2013, 2015, 2016), Shi et al. (2014), and Peters-Lidard et al. (2015). Therefore, only the features most relevant to this study are discussed here.

NU-WRF simulates major aerosol species, such as sulfates, nitrates, black carbon, organic carbon, dust, and sea salt, through the Goddard Chemistry Aerosol Radiation and Transport (GOCART) bulk aerosol scheme (Chin et al. 2002, 2007). These aerosol mass concentrations are used to derive the $\mathrm{CCN}$ number concentration based on the air temperature and supersaturation (Koehler et al. 2006) and the IN number concentration based on an empirical function depending on temperature and aerosol concentration (DeMott et al. 2010; Shi et al. 2014). The estimated CCN is then applied to the autoconversion following the Liu and Daum (2004) formula. The estimated IN number concentrations are applied to the grid-scale cloud physics through the Goddard microphysics scheme as described in W.-K. Tao et al. (2003) and Lang et al. (2011), in which IN influences the conversion of ice crystals to snow and the growth of cloud liquid water to cloud ice. Aerosol mass concentrations are also applied to calculate AOD, single-scattering albedo, and asymmetry factor as inputs to a radiative transfer model to simulate aerosol interactions with radiation (Shi et al. 2014) and the associated temperature changes.

\section{The SAL event of 24-25 August 2013}

This study examines a significant SAL outbreak during 24-25 August 2013 whose early evolution is highlighted in MODIS imagery from NASA's Aqua and Terra satellites (Fig. 1). As the dust outbreak advanced westward, convection was found most prominently along the southern border of the dust layer, suggesting suppression of deep convection within the dust region. 

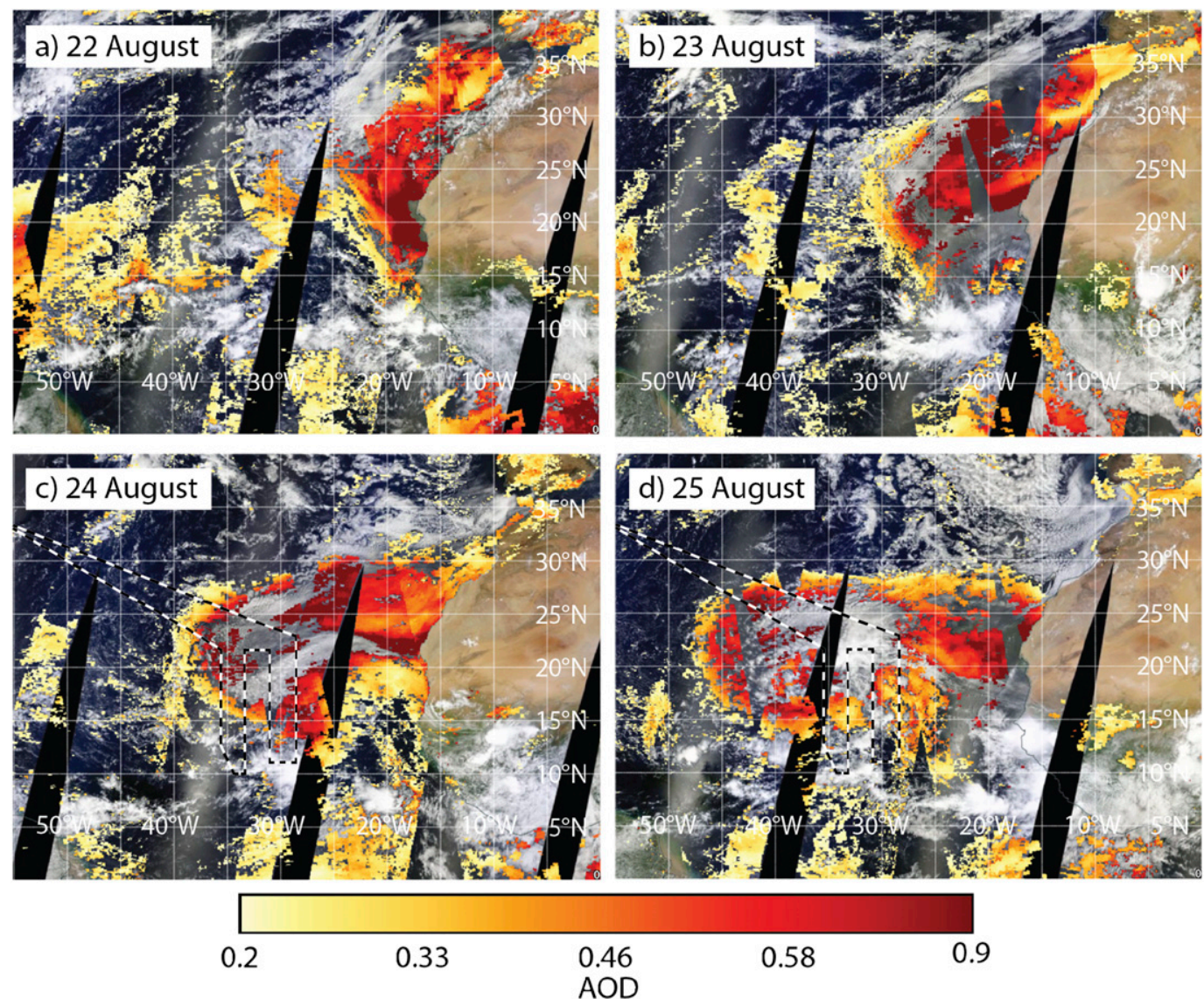

FIG. 1. Daily daytime MODIS AOD (colors) and clouds from Aqua and Terra on (a) 22 Aug, (b) 23 Aug, (c) 24 Aug, and (d) 25 Aug 2013. (c),(d) The Global Hawk flight path for 24-25 Aug, with the time on station being between the times of the two images.

Extensive regions of low clouds are seen beneath the dust layer (visible in MODIS AOD data gaps in Figs. 1c and $1 \mathrm{~d}$ since AOD is retrieved under cloud-free conditions). The flight track (Figs. 1c,d) consisted of a so-called "lawnmower pattern" with four north-south-oriented legs, moving from west to east over the course of the flight. The time on station in the lawnmower flight pattern spanned the period from $\sim 1800$ UTC 24 August to 0330 UTC 25 August, while the images in Figs. 1c and 1d in the region of the dust outbreak corresponded approximately to 1400 UTC.

Figure 2a illustrates the dropsonde measurements of wind and relative humidity (RH) at $800 \mathrm{hPa}$. Dropsonde locations have been adjusted to a reference time of 0000 UTC 25 August using an assumed zonal wave motion of $8 \mathrm{~m} \mathrm{~s}^{-1}$. The background image is the Meteosat SAL product (Dunion and Velden 2004) for 0000 UTC 25 August. The SAL satellite product algorithm is sensitive to the presence of dry and/or dusty air in the lower to midtroposphere $(\sim 850-600 \mathrm{hPa})$. The dropsonde wind data indicate that the strongest easterlies were between $18^{\circ}$ and $23^{\circ} \mathrm{N}$ along the southern boundary of the SAL region in Fig. $2 \mathrm{a}$ and in the southern portion of the highAOD region in the MODIS product. Peak AEJ winds occurred near 600-700 hPa. Weaker easterlies occurred farther to the south, suggesting a weak cyclonic circulation along the southern border of the SAL (see Fig. 2b, which shows the AEW-relative flow), with the trough axis approximately between the second and third flight legs. The dropsonde temperature measurements (Fig. 2b) indicate the warmest air temperatures in the region just north of the circulation center (marked as " $X$ " in Fig. 2), with temperatures warming about $8 \mathrm{~K}$ across the SAL boundary along the second flight leg over a distance of about $11^{\circ}$ of latitude $(\sim 1200 \mathrm{~km})$. Figure 2 shows hot and dry air wrapping around the northern and western sides of the wave and cooler and moister air wrapping around the southern and eastern sides. Deep convective clouds (Fig. 1) were generally confined to the ITCZ region between $\sim 6^{\circ}$ and $13^{\circ} \mathrm{N}$, but little to no precipitation occurred within the AEW, consistent with the humidity and temperature data seen in Fig. 2. 


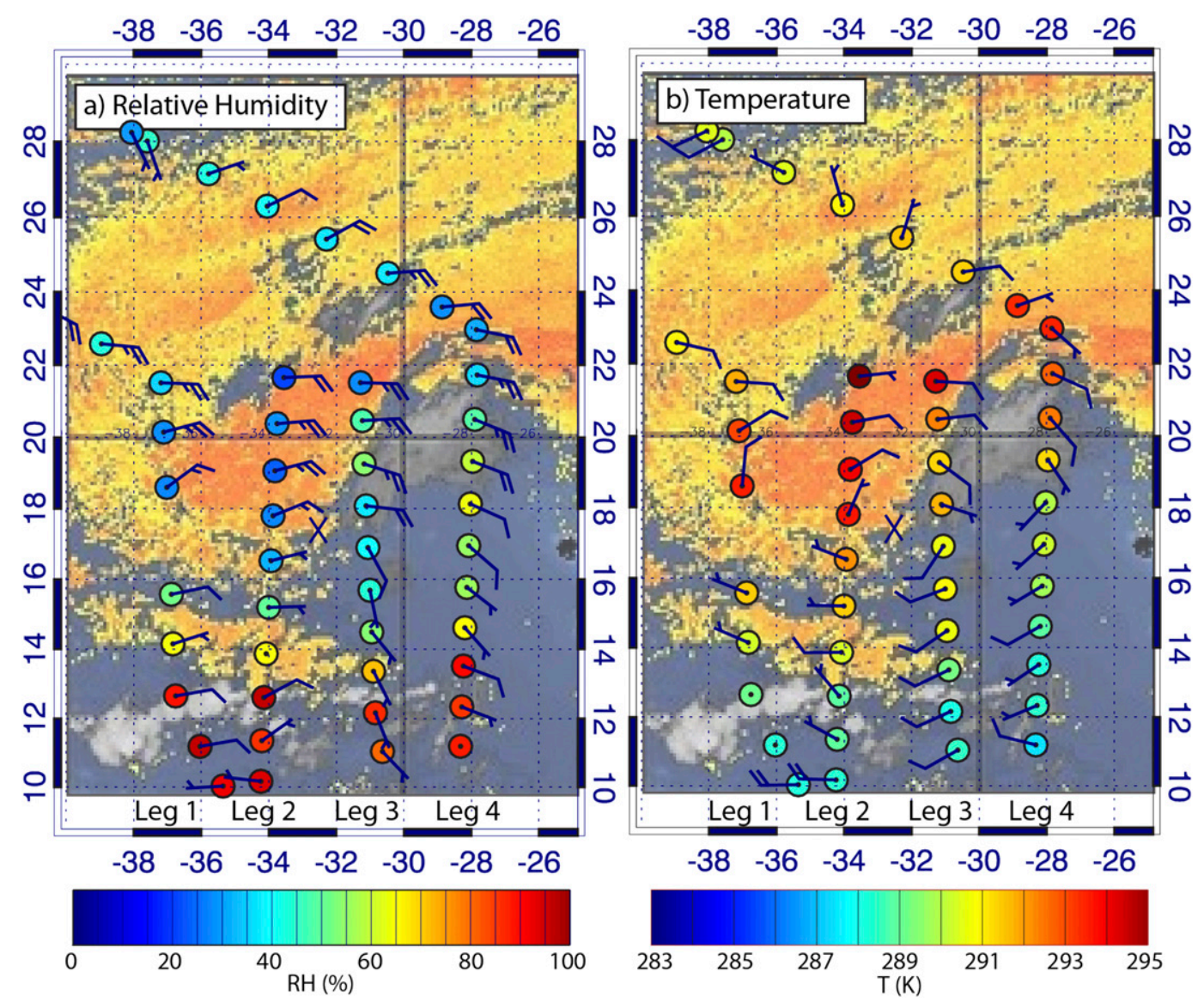

FIG. 2. (a) RH and wind barbs (half barb $=2.5 \mathrm{~m} \mathrm{~s}^{-1}$, full barb $=5 \mathrm{~m} \mathrm{~s}^{-1}$ ) at $800 \mathrm{hPa}$ measured by dropsondes during the 24-25 Aug flight. (b) Temperature and wave-relative wind barbs at $800 \mathrm{hPa}$. Wave-relative flow determined by subtracting the zonal wave motion from the dropsonde winds in (a). The dropsonde data are overlaid on the Meteosat SAL product (Dunion and Velden 2004) for 0000 UTC 25 Aug.

The flow within the AEW plays a fundamental role in shaping the distribution of dust. To our knowledge, the HS3 observations provide the most detailed threedimensional mapping of SAL characteristics within an AEW. Ismail et al. (2010) showed lidar aerosol and water vapor measurements in multiple AEWs during the NAMMA field experiment (Zipser et al. 2009), but flight patterns were not geared toward mapping the 3D structure of the waves, and measurements were typically obtained just along the southern boundary of the SAL. The set of north-south cross sections from HS3 provide a broader-scale mapping of the dust, wind, and thermodynamic structures of the SAL, spanning the region of cyclonic circulation in the AEW. Measurements from CPL show the vertical structure of the dust along the four flight legs (Fig. 3). The vertical structures varied distinctly from one flight leg to the next. For example, in leg 1 (from around $13^{\circ}$ to $21^{\circ} \mathrm{N}$ ), the top of the dust layer increased gradually from approximately 3.5 to $5.5 \mathrm{~km}$, with dust south of $18^{\circ} \mathrm{N}$ being concentrated within an elevated layer of $1-1.5-\mathrm{km}$ thickness, and the dust layer top dropping rapidly on the northern side of the dust layer near $24^{\circ} \mathrm{N}$. In leg 2 , the top of the elevated layer of high backscatter was relatively constant at $4 \mathrm{~km}$ from $13^{\circ}$ to $16^{\circ} \mathrm{N}$ and then dropped sharply to $2.5 \mathrm{~km}$ by $18^{\circ} \mathrm{N}$. Between $18^{\circ}$ and $21.5^{\circ} \mathrm{N}$, the top of the dust layer increased from $\sim 3.2$ to $5.2 \mathrm{~km}$. An optically thick stratocumulus cloud deck topped the boundary layer beneath the dust layer, preventing lower-level measurements. In leg 3, a break occurred between the deeper layer of dust to the north and the elevated dust layer to the south. Finally, leg 4 shows a pattern similar to leg 3; however, upper-level clouds (with tops at or above $7 \mathrm{~km}$ ) severely attenuated profiling of the dust layer between $\sim 19^{\circ}$ and $23^{\circ} \mathrm{N}$, so the southern extent of the northern region of dust cannot be determined. It is unclear whether the clouds were associated with convection in the AEW, given that just above the boundary layer, relative humidity in the area was relatively low ( $\sim 60 \%$; Fig. $2 a)$ and temperatures 

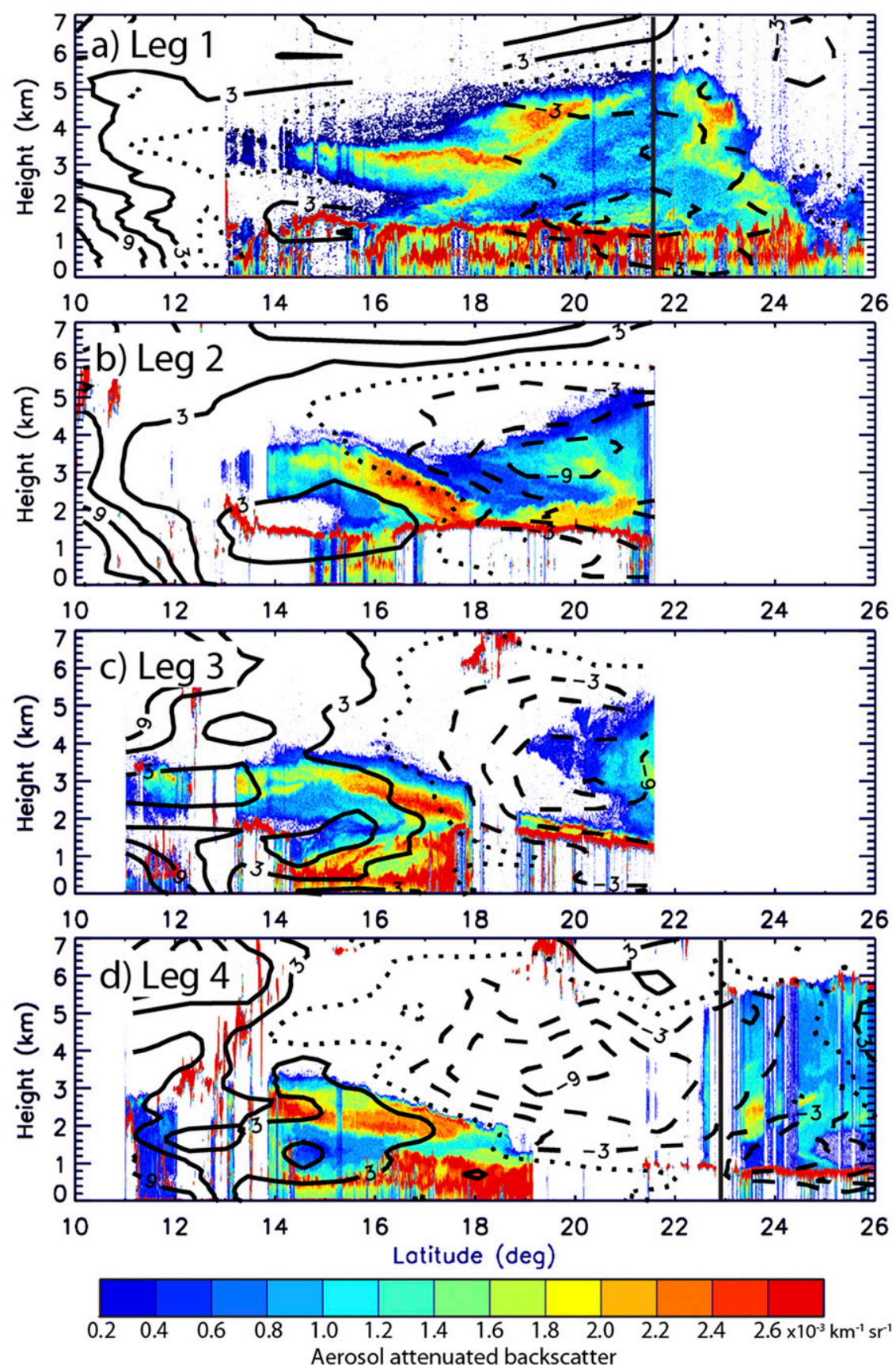

FIG. 3. (a)-(d) Vertical cross sections of aerosol ATB measured by CPL (shading) and waverelative zonal wind (contours) from dropsondes from west (leg 1) to east (leg 4) during the 24-25 Aug flight. For zonal wind, the contour interval is $3 \mathrm{~m} \mathrm{~s}^{-1}$, with positive values solid, negative values dashed, and the 0 contour dotted. In (a) and (d) vertical lines indicate the locations of turns at the end of the inbound flight leg (leading into the lawnmower pattern) and at the beginning of the outbound leg (exiting the lawnmower pattern, heading back toward the United States), respectively.

were warm (Fig. 2b), or whether they were associated with an upper-level stratus deck.

Figure 3 also shows the wave-relative zonal wind component determined by subtracting the approximate
$8 \mathrm{~m} \mathrm{~s}^{-1}$ zonal wave motion from the dropsonde zonal winds. In legs $2-4$, the sloping zone of high dust backscatter south of $18^{\circ} \mathrm{N}$ occurred near the transition between easterly and westerly flow in the wave-relative 

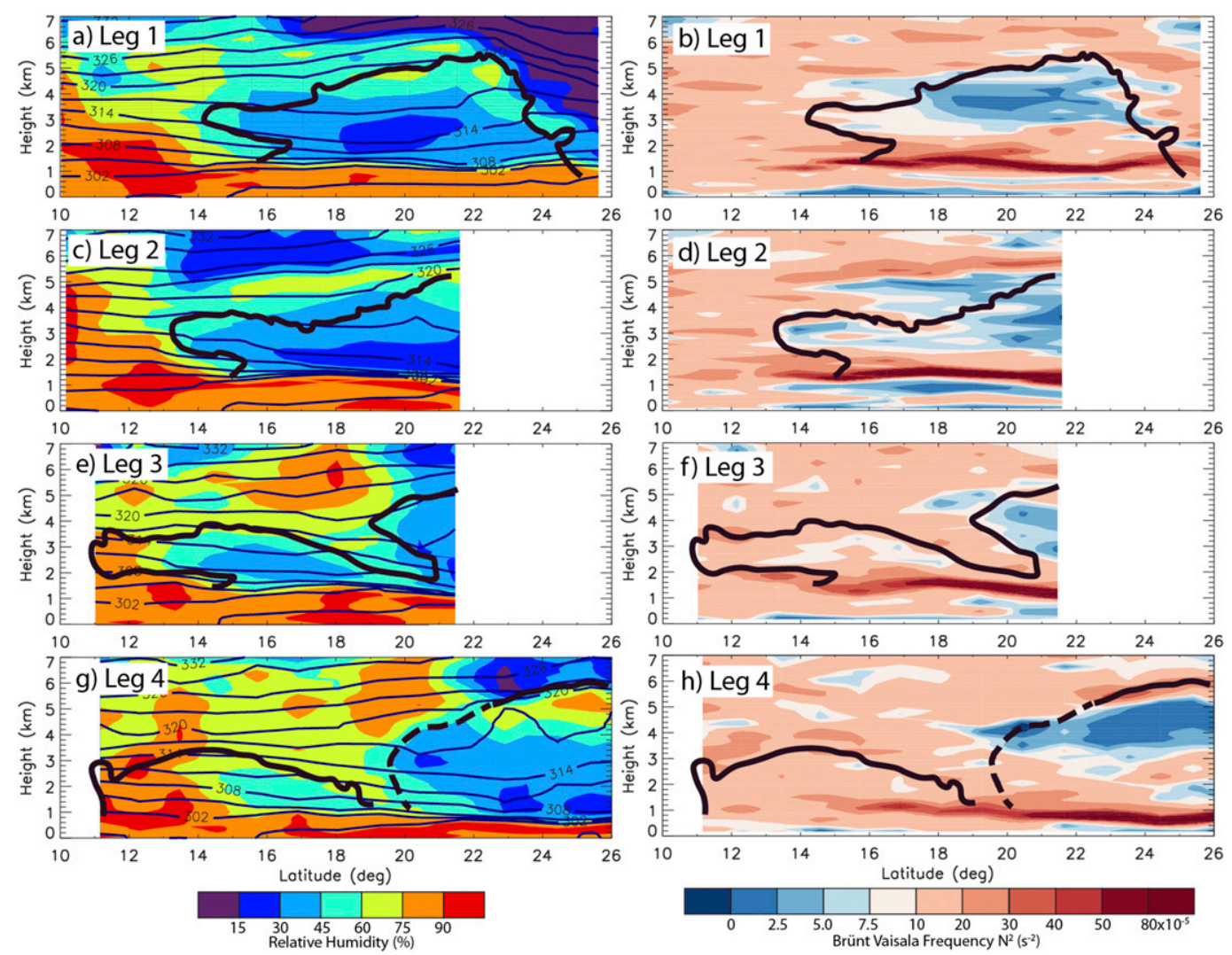

FIG. 4. (a),(c),(e),(g) Vertical cross sections of RH (shading) and potential temperature (contours, 3-K intervals) from dropsondes from west (leg 1) to east (leg 4) during the 24-25 Aug flight. (b),(d),(f),(h) Vertical cross sections of Brunt-Väisälä frequency. Thick black outlines indicate the approximate boundaries of Saharan dust in each cross section. The dashed lines in $(\mathrm{g})$ and $(\mathrm{h})$ indicate a best guess of the boundaries based upon available ATB and dropsonde data.

flow, which also was sloped toward the south with increasing height. Thus, the elevated dust layer to the south of the vortex center was associated with westerly wave-relative flow, while almost no dust was present in the easterly flow at higher levels at these latitudes. The deeper dust layer to the north of the vortex center was associated with the stronger easterlies in the AEJ, with most of the dust in legs 2-4 located to the north of the jet axis. The AEJ was centered near $20^{\circ} \mathrm{N}$ and $3-4-\mathrm{km}$ $(700-620 \mathrm{hPa})$ altitude in legs 2 and 4, with peak zonal winds (ground relative) between 17 and $20 \mathrm{~m} \mathrm{~s}^{-1}$. In leg 3 , the AEJ was centered slightly lower, near $2.9 \mathrm{~km}$ $(720 \mathrm{hPa})$, with a magnitude of about $21 \mathrm{~m} \mathrm{~s}^{-1}$. The primary dust layer to the north of the AEJ is consistent with the conceptual model of Karyampudi and Carlson (1988) and Karyampudi et al. (1999), but in this event, advection of dust around the cyclonic center of the wave extended the dust layer well south of the jet.

The thermodynamic structure in each of the flight legs is shown in Fig. 4, with the left panels showing the relative humidity and potential temperature fields and the right panels showing the atmospheric static stability given by the Brunt-Väisälä frequency $N^{2}=\left(g / \theta_{v}\right)\left(\Delta \theta_{v} \mid \Delta z\right)$, where $g=9.81 \mathrm{~m} \mathrm{~s}^{-2}, \theta_{v}$ is the virtual potential temperature, and $z$ is altitude. In each cross section, in the region of deeper dust embedded in the easterly wave-relative flow, very dry conditions existed above the moist boundary layer, with relative humidity between $15 \%$ and $45 \%$, consistent with many past studies (Carlson and Prospero 1972; Karyampudi and Carlson 1988; Ott et al. 1991; Parker et al. 2005). Relative humidity increased near the top of the dust layer to values between $50 \%$ and $75 \%$, with values exceeding $75 \%$ in the northern part of leg 4 . The higher humidity near the top of the SAL was also found by Parker et al. (2005) and Messager et al. (2010).

Isentropes were tightly spaced at the base of the SAL but spread apart within the SAL, consistent with expectations arising from the fact that the SAL is an elevated mixed layer (Carlson and Prospero 1972; Ott et al. 1991). The resulting static stability profiles show a shallow layer of extremely high $N^{2}\left(>50 \times 10^{-5} \mathrm{~s}^{-2}\right)$ at the top of the boundary layer 
that weakened south of $\sim 14^{\circ} \mathrm{N}$. Very low values of $N^{2}$ were found within and just above the dust layer, with some regions of $N^{2}<2.5 \times 10^{-5} \mathrm{~s}^{-2}$. These low values reflect the nearly dry adiabatic vertical mixing that occurred several days earlier over the Sahara and are similar to values shown by Parker et al. (2005) for a transect over the Sahara. To the south of the vortex center (south of $\sim 17.5^{\circ} \mathrm{N}$ ), the region of lower stability $\left(N^{2}<0.0001 \mathrm{~s}^{-2}\right)$ was apparent to the west of the center (leg 2) and diminished to the east of the center (legs 3 and 4). In contrast, the very high stability at the base of the SAL extended well southward of the center (to $13^{\circ}-14^{\circ} \mathrm{N}$ ) in all four flight legs, thereby suppressing convection within the wave. Given the latitude of the wave center and the clear suppression of convection by the SAL, the 24-25 August AEW fits the typical pattern of nondeveloping waves described by Bretl et al. (2015).

\section{NU-WRF configuration and experiment setup}

Figure 5 illustrates the experiment domains centered over the Global Hawk flight area with horizontal spatial resolutions of 15 and $3 \mathrm{~km}$ for the outer and inner $(\mathrm{d} 02)$ domains, respectively. There are $450 \times 360$ and $725 \times 820$ horizontal grid cells for the outer and inner domains, respectively. Sixty vertical levels extend from surface to $50 \mathrm{hPa}$. The simulation period is from 0000 UTC 20 August to 0000 UTC 26 August 2013, allowing for a 3-day model spinup prior to the period of interest. The key NU-WRF Model physics include the Goddard cloud microphysics (Tao et al. 2011) and the Goddard longwave/shortwave radiation scheme (Chou and Suarez 1999), both of which are coupled with the GOCART bulk aerosol scheme to represent the aerosol direct and indirect effects (Shi et al. 2014).

The anthropogenic emissions were based on the Emissions Database for Global Atmospheric Research (EDGAR) developed by the Joint Research Centre of the European Commission (EC-JRC; EDGAR version 4.2; http://edgar.jrc.ec.europa.eu/). Fire emissions were derived from the Fire Inventory from NCAR, version 1 (FINNv1; Wiedinmyer et al. 2011), and the ambient environmental conditions and fire-size information were used to calculate the smoke injection heights (Freitas et al. 2007; Sessions et al. 2011). The Model of Emissions of Gases and Aerosols from Nature, version 2 (MEGAN2; Guenther et al. 2006), was employed to estimate the biogenic emissions. Dust emissions were calculated online following the method by Ginoux et al. (2001) based on surface wind speed, soil moisture, and soil erodibility. Sea salt emissions were calculated by the parameterization based on Gong (2003).

The meteorological initial and lateral boundary conditions were derived from the 6-hourly European Centre

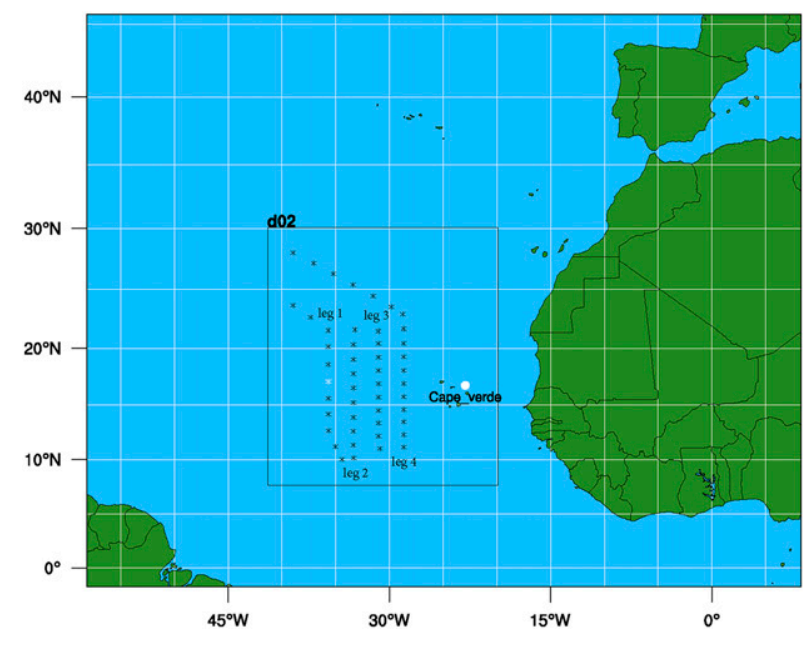

FIG. 5. Model domains for the NU-WRF experiments. Asterisks represent the dropsonde locations along the Global Hawk flight path. The white dot denotes the AERONET site at Cape Verde. Legs 1-4 indicate the locations of cross sections shown in Figs. 2-4.

for Medium-Range Weather Forecasts (ECMWF) interim reanalysis (ERA-Interim) global reanalysis data (Dee et al. 2011). The chemical initial and lateral boundary conditions were obtained from global GOCART (Chin et al. 2007) simulations that also used EDGARv4 emissions with a resolution of $1.25^{\circ}$ (longitude) by $1^{\circ}$ (latitude).

Validation of the simulation is achieved through comparison of simulated fields with Global Hawk, ground, and satellite observations. The model simulations were evaluated using the temperature, $\mathrm{RH}$, and wind data measured by the dropsonde system; the attenuated backscatter measured by the CPL; and the AOD data collected from AERONET and MODIS.

To address the atmospheric response to the microphysical and radiative effects of dust and other aerosols, four sets of simulations have been conducted as summarized in Table 1 . The following equations define the dust and other aerosol contribution to meteorological parameters (defined as $f$, where $f$ may be temperature, $\mathrm{RH}$, winds, etc.) relative to a simulation excluding aerosol effects $\left(f_{0}\right)$ :

Effect of aerosol-microphysics interaction (AM)

$$
=f_{\mathrm{AM}}-f_{0} \text {, }
$$

Effect of aerosol-radiation interaction (AR)

$$
=f_{\mathrm{AR}}-f_{0},
$$

Effect of combined aerosol-microphysics

$$
\text { -radiation interaction }(\mathrm{AMR})=f_{\mathrm{AMR}}-f_{0} \text {. }
$$

It should be noted that the summation of AM and AR is not necessarily equal to AMR. The difference can 
TABLE 1. NU-WRF numerical experiment design.

\begin{tabular}{ll}
\hline \hline \multicolumn{1}{c}{ Expt } & \multicolumn{1}{c}{ Feedbacks included } \\
\hline NoAMR & No aerosol-microphysics-radiation interactions \\
AM & Aerosol-microphysics interaction only \\
AR & Aerosol-radiation interaction only \\
AMR & Aerosol-microphysics-radiation interactions \\
\hline
\end{tabular}

be characterized as the synergistic effect between $\mathrm{AM}$ and $\mathrm{AR}$ following the convention by Stein and Alpert (1993) and Z. Tao et al. (2003). The synergistic effect reflects the dynamical interaction between AM and AR.

\section{Results and analysis}

\section{a. General SAL features and comparison to observations}

The results from experiment AMR were chosen as the baseline for comparisons to observations and other simulations. The depiction of the general SAL features is given in Fig. 6 based on the results from the $15-\mathrm{km}$ domain. All fields are snapshots at the passing time (around 1030 LST) of the Terra satellite carrying MODIS on 24 August (Fig. 1c), with the exception of precipitation, which represents the 2-day total accumulation for 24-25 August. Figure 6a shows the simulated total AOD at $550 \mathrm{~nm}$ overlaid with $850-\mathrm{hPa}$ winds. In comparison with the MODIS measurements (Fig. 1c), NU-WRF simulates the AOD spatial distribution well, including two regions of higher AOD separated by a narrow east-west-oriented zone of lower AOD near $23^{\circ}-24^{\circ} \mathrm{N}, 16^{\circ}-27^{\circ} \mathrm{W}$. However, the simulated AOD is generally lower (up to a factor of 2 in some regions) than the MODIS measurements. The warmest air near the wave axis (around $24^{\circ} \mathrm{W}$ ) is $\sim 295-297 \mathrm{~K}$ (Fig. 6b), which is close to the values observed by dropsondes nearly $12 \mathrm{~h}$ later (Fig. 2). The transition from easterly to westerly flow in the wave occurs near $10^{\circ} \mathrm{N}$ (Figs. 6a,b), consistent with the dropsonde data (Fig. 2a). Relative humidity values in the SAL (Fig. 6 c) are between $20 \%$ and $40 \%$, also in agreement with the observations. The modeled precipitation lies primarily between $6^{\circ}$ and $12^{\circ} \mathrm{N}$ along the southern boundary of the SAL outbreak, in agreement with that implied by the cloud imagery in Fig. 1 . Similar to the observations, NU-WRF simulates an AEJ between $18^{\circ}$ and $23^{\circ} \mathrm{N}$ across the trough axis, as seen in the winds at $700 \mathrm{hPa}$ in Fig. $6 \mathrm{~d}$. The simulated maximum wind speed in the AEJ reaches $19 \mathrm{~m} \mathrm{~s}^{-1}$, within the range of the observed $17 \sim 20 \mathrm{~m} \mathrm{~s}^{-1}$.

Next, we performed a more detailed evaluation of the model by comparing simulated variables to AERONET AOD data, HS3 dropsondes, and CPL observations.
The simulated fields were taken from the $3-\mathrm{km}$ resolution domain (d02) shown in Fig. 5. Figure 7 shows the comparison of the 24-25 August daytime-only hourly AOD at $550 \mathrm{~nm}$ between NU-WRF and the respective AERONET measurements. NU-WRF AOD values are well correlated (correlation coefficient of 0.83 ) with AERONET observations; however, NU-WRF underestimates the AOD by $\sim 18 \%$, consistent with the finding that NU-WRF underestimates the AOD, compared to MODIS measurements.

Figure 8 compares the mean differences between simulated and dropsonde-observed temperature, $\mathrm{RH}$, and winds for the AMR and NoAMR experiments. Comparison statistics are listed in Table 2. For this analysis, simulated profiles were obtained for each of 47 dropsonde locations and times, and then the differences between simulated and observed values were averaged. Overall, NU-WRF simulates the air temperature profile very well, with a 0.99 correlation coefficient and small positive bias above the boundary layer (Fig. 8a). Because the temperature error above the boundary layer is positive in the NoAMR run, and because dust contributes to warming of the dust layer when AMR interactions are included, the overall warm bias is about $0.03 \mathrm{~K}$ higher in AMR, compared to that in NoAMR (Table 2). For RH, both NU-WRF runs perform very well within the SAL, with the exception of an enhanced dry bias at the top of the SAL, where the simulations produce insufficient moistening associated with the dry convective mixing that produces the SAL (Messager et al. 2010; Braun 2010). In general, NU-WRF underestimates RH at midlevels $(800-500 \mathrm{hPa})$ and overestimates RH above $400 \mathrm{hPa}$, leading to an overall wet bias of about $8 \%$ for the AMR case. For the wind speed and direction vertical profiles, errors are generally within $\pm 1.5 \mathrm{~m} \mathrm{~s}^{-1}$ and $20^{\circ}$, with larger errors above $400 \mathrm{hPa}$.

To evaluate the model performance in the SAL-only environment, 32 dropsonde profiles were identified as being within the SAL based on their potential temperature/humidity profiles and were compared to the corresponding model profiles. The resulting statistics are comparable to those with all 47 dropsondes. Taking the AMR experiment as an example, bias and RMSE statistics of the SAL-only case versus all dropsondes are slightly worse for temperature $(0.89$ vs $0.78 \mathrm{~K}$ for bias and 1.70 vs $1.65 \mathrm{~K}$ for RMSE) and wind speed $\left(-0.78 \mathrm{vs}-0.77 \mathrm{~m} \mathrm{~s}^{-1}\right.$ for bias and $1.37 \mathrm{vs} 1.22 \mathrm{~m} \mathrm{~s}^{-1}$ for RMSE), but better for RH $(7.38 \%$ vs $7.71 \%$ for bias and $20.48 \%$ vs $21.17 \%$ for RMSE) and wind direction $\left(-4.28^{\circ}\right.$ vs $6.18^{\circ}$ for bias and $11.33^{\circ}$ vs $17.34^{\circ}$ for RMSE). The correlation coefficients, however, improve for all variables ( 0.83 vs 0.76 for $\mathrm{RH}, 0.89$ vs 0.87 

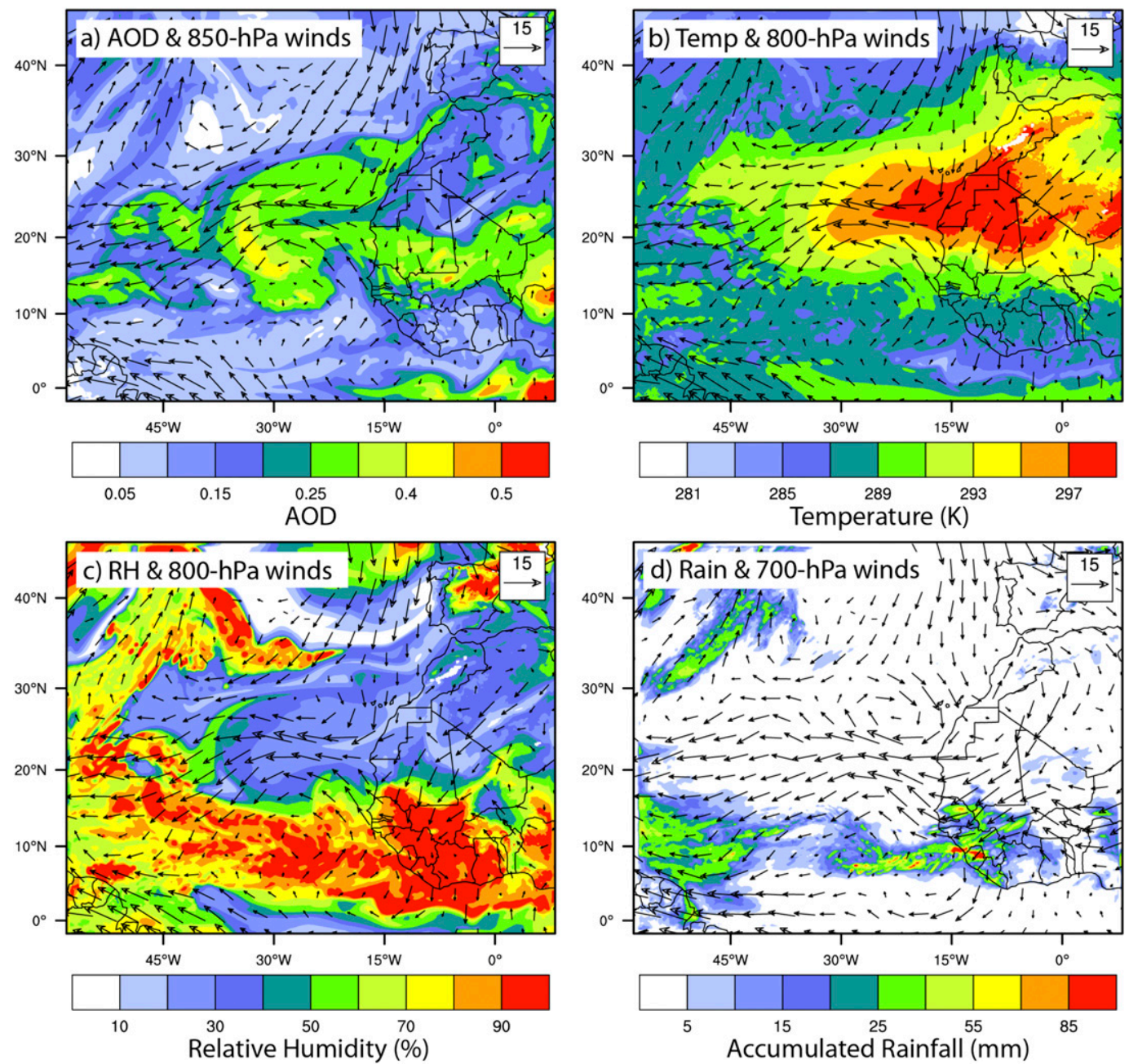

FIG. 6. NU-WRF-simulated (a) total 550-nm AOD and 850-hPa winds, (b) 800-hPa temperature and winds, (c) 800-hPa RH and winds, and (d) 24-25 Aug 2-day total precipitation accumulation and 700-hPa winds. All fields except precipitation in (d) obtained from instantaneous fields at 1200 UTC 24 Aug.

for wind speed, 0.96 vs 0.84 for wind direction, and 0.99 vs 0.99 for temperature) in the SAL-only environment. Overall, NU-WRF captures the wind profiles reasonably well, as indicated by the relatively high correlation coefficients.

The Goddard Satellite Data Simulator Unit (G-SDSU) can compute radiances or backscatter signals from various model-simulated atmospheric profiles, including clouds, precipitation, and aerosols (Matsui et al. 2013, 2014). The computed radiances or lidar attenuated total backscatter (ATB) can then be compared directly to satellite and/or aircraft remote sensing measurements. In this study, the lidar simulator in the G-SDSU was employed to calculate the lidar backscatter at $1064 \mathrm{~nm}$ from the NU-WRF-simulated geophysical parameters, including Rayleigh and aerosols/cloud backscatters. The modeled vertical cross-sections of ATB along the four flight legs were compared against measurements from the 1064-nm channel from CPL (Fig. 3). An example of simulated ATB from flight leg 2, with RH overlaid, is shown in Fig. 9a, while the corresponding observations (Figs. 3b, 4c) are replotted in Fig. 9b. Most of the simulated dust layer (ATB $>0.2 \times 10^{-3} \mathrm{~km}^{-1} \mathrm{sr}^{-1}$ ) shows a structure and depth (up to $\sim 5 \mathrm{~km}$ ) that matches quite closely with the CPL data, except that the simulated ATB is about $20 \%-30 \%$ lower than observed, consistent with the lower simulated AOD, compared to AERONET measurements. The model captures the presence of a low-level cloud layer at the top of the boundary layer beneath the SAL, including a region north of $\sim 18^{\circ} \mathrm{N}$ in which the clouds cause complete attenuation of the lidar signal. South of $\sim 15^{\circ} \mathrm{N}$, the model reproduces the cloud layer above 9-km altitude. 


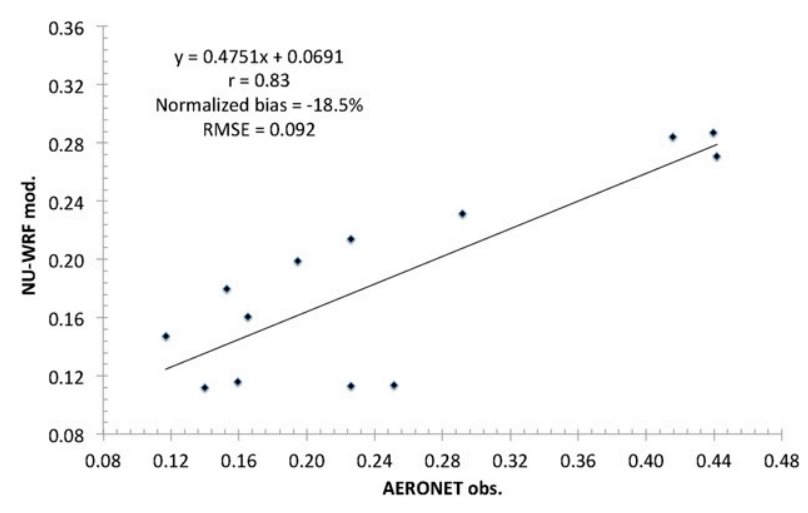

FIG. 7. Comparison of NU-WRF-modeled vs AERONETmeasured hourly AOD at $550 \mathrm{~nm}$ during daytime hours at Cape Verde (indicated by the white dot in Fig. 5).

The air within the low-level SAL near 2-km altitude, in both the observations (Fig. 9b) and simulation (Fig. 9a), is quite dry, with RH values less than $30 \%$. In the observations, above this dry layer, the $\mathrm{RH}$ increases slowly with height up to the top of the dust layer and then increases more quickly to values exceeding $60 \%$ in a thin layer at the top of the SAL near 5-5.5-km altitude (Parker et al. 2005; Messager et al. 2010; Braun 2010). Above this thin higher-RH layer north of $14^{\circ} \mathrm{N}$, RH generally drops below $30 \%$, except for another thin layer near $7.5 \mathrm{~km}$ in which RH exceeds a value of $30 \%$ to the south and $60 \%$ to the north. In the simulation, a similar increase in $\mathrm{RH}$ with height occurs within the dust layer, with RH reaching values of $45 \%-60 \%$ just below the top of the dust layer. The RH falls below $30 \%$ above the dust layer, as observed, and then increases to values in excess of $60 \%$ in the $7-8-\mathrm{km}$ layer, values that are $20 \%-30 \%$ higher than observed, before falling to very low values at higher altitudes.

In summary, NU-WRF simulated this SAL event reasonably well. Although there were quantitative differences between the observed and simulated AOD, ATB, and RH, the model reasonably captured the major atmospheric conditions and the three-dimensional dust distribution.

\section{b. Aerosol effects on the SAL vertical structure}

Following Eqs. (1)-(3), we were able to evaluate the impact of aerosols on meteorological conditions within and adjacent to the SAL. The following analysis is based on zonal-mean results from the inner domain (d02) averaged over 24-25 August. Twenty grid points along each edge of the domain were excluded from the analysis to minimize the impact of the domain boundaries and the coarser outer nest. The Student's $t$ test has been used to determine if differences in the zonal means of various parameters between the experiments and the NoAMR simulation are statistically significant. For the difference fields, only statistically significant differences at the $99 \%$ confidence level are plotted, while insignificant differences are represented as white space in the figures.

\section{1) AtMospheric HeAting AND temPerature}

Dust aerosols absorb solar radiation and alter cloud optical properties that can lead to changes in atmospheric heating profiles. Figure 10a shows the zonalmean net longwave and shortwave heating rate. Net cooling dominates levels below $400 \mathrm{hPa}$, with the strongest cooling near the base of the SAL. Net heating occurs within clouds above $400 \mathrm{hPa}$ south of $\sim 22^{\circ}-24^{\circ} \mathrm{N}$ (see the mean cloud/hydrometeor fields in Fig. 14a), highlighting the importance of cloud-radiative feedbacks aloft. Also shown is the NoAMR zonal-mean dust mixing ratio field for reference, with the pattern of dust strongly resembling the dust distributions in Fig. 2, particularly the elevated layer of dust to the south. Figures 10b-d show the differences in net radiative heating rates between the AM, AR, and AMR simulations and the simulation without any aerosol impacts (NoAMR). In the SAL region (to the north of $14^{\circ} \mathrm{N}$ ), the presence of dust overall (Fig. 10d) leads to slightly stronger cooling near the surface, stronger heating $\left(>0.5 \mathrm{~K} \mathrm{day}^{-1}\right.$ in the zonal average) within a thin layer near the bottom of the dust layer, and weak heating $\left(<0.2 \mathrm{~K} \mathrm{day}^{-1}\right)$ within the remainder of the dust layer $(\sim 800-500 \mathrm{hPa})$. The strong heating increase within the thin layer near the base of the dust layer is largely caused by the longwave absorption within the stratocumulus cloud deck at the top of the boundary layer that is enhanced by the AM effect (figures now shown). Above the SAL, cooling occurs between 500 and $300 \mathrm{hPa}$ and is particularly pronounced near the upper ITCZ region north of $12^{\circ} \mathrm{N}$. The AR effect (Fig. 10c) is the major driving force of the change in radiative heating profiles below $400 \mathrm{hPa}$, while both the AM (Fig. 10a) and AR effects are important to the changes in atmospheric heating above $400 \mathrm{hPa}$. Although not shown here, an examination of the contributions from shortwave and longwave processes reveals that the dust enhances shortwave heating within the SAL mainly through the AR effect, but also increases longwave cooling, consistent with Carlson and Benjamin (1980). The net effect is weaker heating within the SAL. To the south of $16^{\circ} \mathrm{N}$ and between 300 and $200 \mathrm{hPa}$ in the vicinity of upperlevel clouds, the AM and AR effects of the Saharan dust apparently alter cloud-radiative interactions. The AM effect (Fig. 10b) leads to a mix of warming and cooling in the cloudy region, while the AR effect (Fig. 10c) leads to warming south of $11^{\circ} \mathrm{N}$ and strong cooling (up to $1.5 \mathrm{~K} \mathrm{day}^{-1}$ ) between $12^{\circ}$ and $15^{\circ} \mathrm{N}$. 

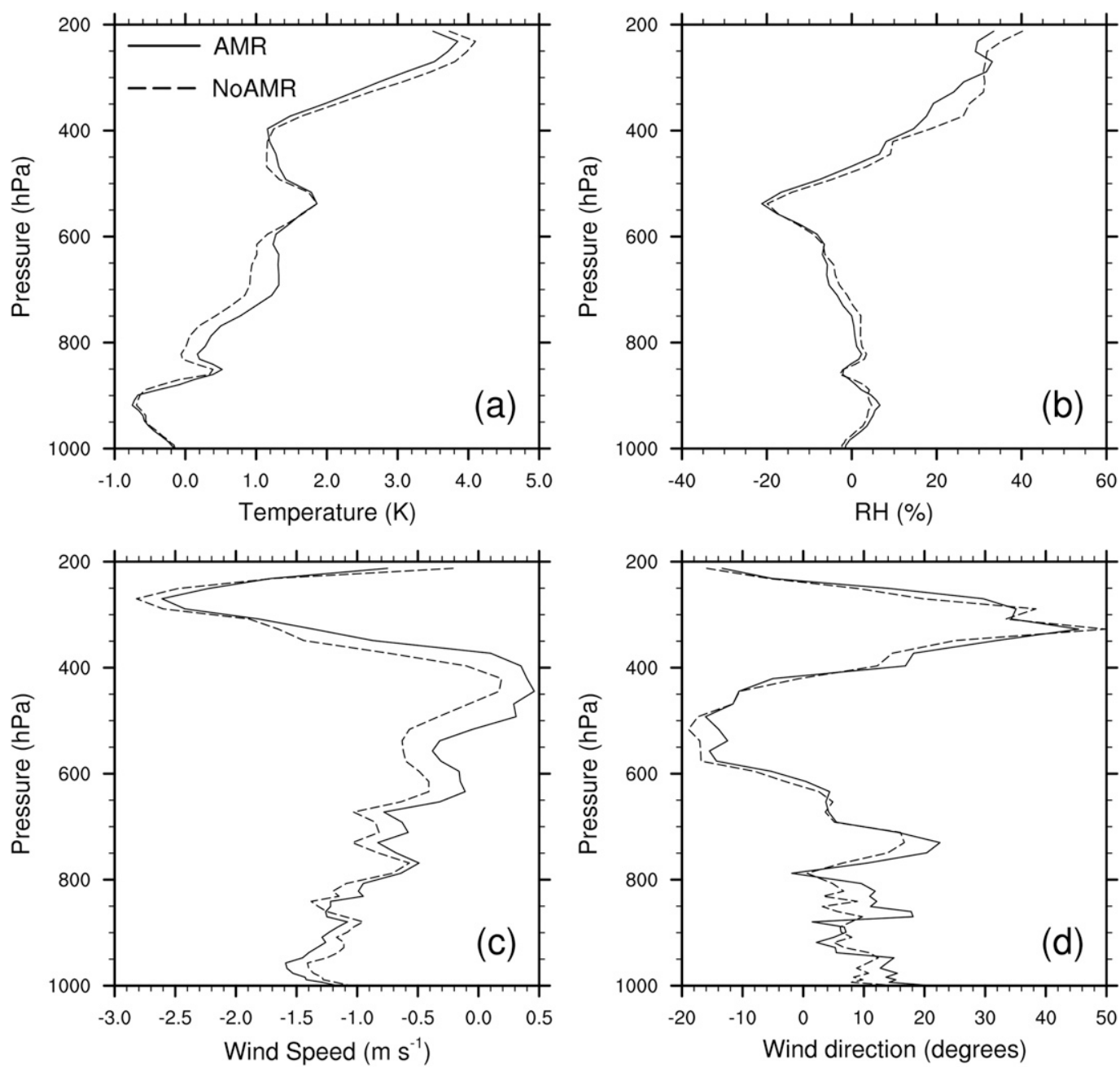

FIG. 8. Comparison of NU-WRF-modeled vs dropsonde-measured (a) temperature $\left({ }^{\circ} \mathrm{C}\right),(\mathrm{b}) \mathrm{RH}(\%)$, (c) wind speed $\left(\mathrm{m} \mathrm{s}^{-1}\right)$, and (d) wind direction $\left(^{\circ}\right)$. Shown are mean errors for 47 dropsondes, compared to simulated profiles at the dropsonde times and locations.

The zonal-mean temperature structure (Fig. 11a) shows the low-level "lens" (Ott et al. 1991) of warm air within the dust layer, with the warmest air residing in the lowest part of the dust layer where dust mixing ratios are largest. The dust-induced air temperature changes are shown in Figs. 11b-d. In general, the AM effect causes only small temperature changes (generally within $\pm 0.2 \mathrm{~K}$ ) within the troposphere (Fig. 11b). The AR effect (Fig. 11c) warms the dust layer, in agreement with Chen et al. (2010), but cools the air above $400 \mathrm{hPa}$, consistent with the pattern of changes in net cloudradiative heating (Fig. 10c). Together, the net effect is dominated by the AR impact with warming within the dust layer (more than $0.2 \mathrm{~K}$ ) and cooling at upper levels

TABLE 2. Statistical comparisons of modeled vs observed meteorological variables.

\begin{tabular}{|c|c|c|c|c|c|c|}
\hline \multirow[b]{2}{*}{ Meteorological variables } & \multicolumn{2}{|c|}{ Correlation coefficient } & \multicolumn{2}{|c|}{ Bias } & \multicolumn{2}{|c|}{ RMSE } \\
\hline & AMR & NoAMR & AMR & NoAMR & AMR & NoAMR \\
\hline Temperature $\left({ }^{\circ} \mathrm{C}\right)$ & 0.99 & 0.99 & 0.78 & 0.75 & 1.65 & 1.69 \\
\hline $\mathrm{RH}(\%)$ & 0.76 & 0.70 & 7.71 & 9.07 & 21.17 & 22.48 \\
\hline Wind speed $\left(\mathrm{m} \mathrm{s}^{-1}\right)$ & 0.87 & 0.91 & -0.77 & -0.87 & 1.22 & 1.22 \\
\hline Wind direction $\left(^{\circ}\right)$ & 0.84 & 0.85 & 6.18 & 3.74 & 17.34 & 15.89 \\
\hline
\end{tabular}




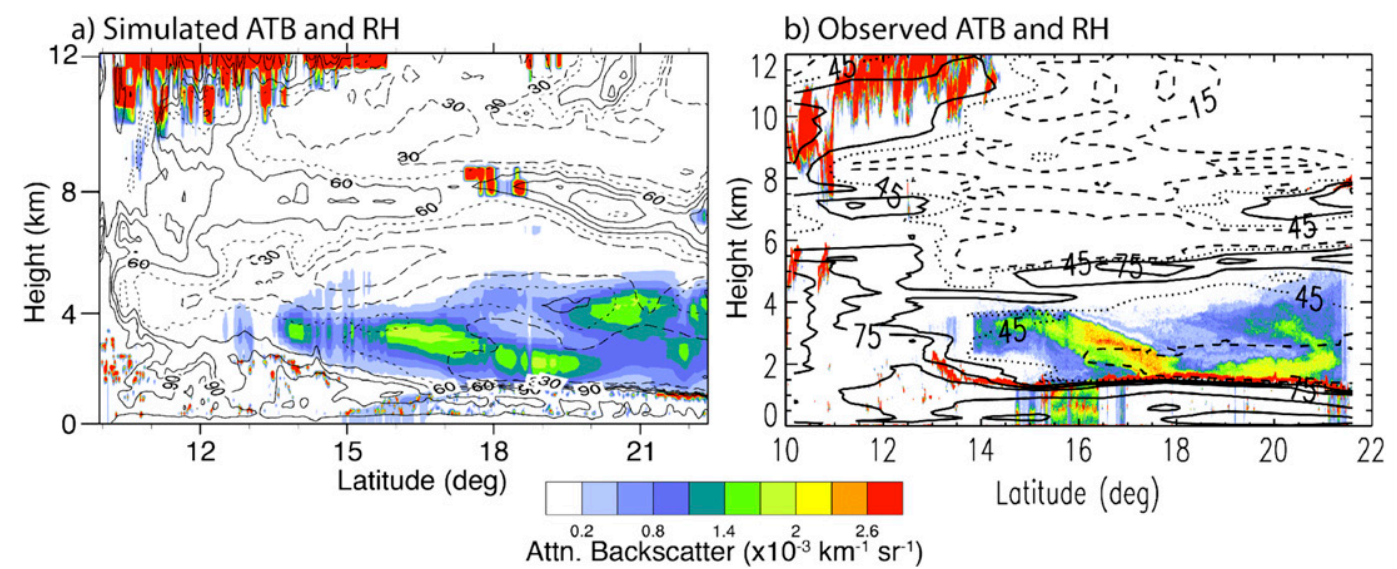

FIG. 9. Comparison of (a) NU-WRF-simulated vs (b) CPL-measured ATB (shading) for flight leg 2 as shown in Fig. 3b. Contours show (a) modeled and (b) dropsonde-measured RH at $15 \%$ intervals; $15 \%$ and $30 \%$ are dashed, $45 \%$ is dotted, and $60 \%-90 \%$ are solid.

(Fig. 11d). This change strengthens the temperature inversion already present without the dust feedback, thereby further enhancing atmospheric stability at the top of the boundary layer (Fig. 4). Warming at low to midlevels in the ITCZ may also contribute to low-level stabilization that can reduce convection there.

\section{2) HORIZONTAL AND VERTICAL WINDS}

Before discussing changes to moisture fields (specific and relative humidity, along with hydrometeor fields), it is necessary to describe changes in atmospheric circulation, especially vertical motions that can drive changes in moisture fields. First, we characterize the zonal- and time-mean wind components from NoAMR (Fig. 12) to which the impacts can be compared. NU-WRF simulated a strong AEJ, with the maximum 2-day average wind speed exceeding $12 \mathrm{~m} \mathrm{~s}^{-1}$ (Fig. 12a). From north to south, the height of the strongest easterly flow gradually increases from around $850 \mathrm{hPa}$ near $24^{\circ} \mathrm{N}$ to around $650 \mathrm{hPa}$ near $20^{\circ} \mathrm{N}$. Easterly flow dominates below $400 \mathrm{hPa}$, except within the boundary layer south of $12^{\circ} \mathrm{N}$ and at most heights north of $27^{\circ} \mathrm{N}$. At high altitudes (above $300 \mathrm{hPa}$ ), tropical easterlies transition to westerlies north of $16^{\circ} \mathrm{N}$, with maximum westerlies of over $8 \mathrm{~m} \mathrm{~s}^{-1}$ north of $24^{\circ} \mathrm{N}$. Meridional and vertical winds are consistent with an overturning Hadley circulation. Southerly flow (Fig. 12b) extends through most of the domain, with maximum values in the boundary layer south of $10^{\circ} \mathrm{N}$ and in the upper troposphere between $18^{\circ}$ and $24^{\circ} \mathrm{N}$. Northerlies are found in the far northern portion of the domain and in the boundary north of $13^{\circ} \mathrm{N}$. Vertical motions (Fig. 12c) show generally subsiding air to the north and rising air to the south, with the transition varying with altitude from $\sim 16^{\circ} \mathrm{N}$ at low levels to $\sim 23^{\circ} \mathrm{N}$ at upper levels. The strongest rising motion is in the ITCZ between $8^{\circ}$ and $12^{\circ} \mathrm{N}$. Interestingly, within the dust layer, the vertical motion pattern is counter to the prevailing Hadley circulation, with rising (sinking) air motions in the northern (southern) portions of the dust layer.

Figure 13 shows the differences in zonally averaged zonal, meridional, and vertical winds between the AM, $\mathrm{AR}$, and AMR simulations and the simulation without any aerosol impacts (NoAMR). The combined AMR effect (Fig. 13c) enhances the AEJ south of $22^{\circ} \mathrm{N}$, with the largest negative difference near $12^{\circ} \mathrm{N}$ at the southern edge of the jet. Dust and other aerosols weaken the easterlies in the boundary layer and increase them within and just above the elevated dust layer between $11^{\circ}$ and $25^{\circ} \mathrm{N}$, implying a slight rise in the jet level (Reale et al. 2011). Easterlies are also weakened above $300 \mathrm{hPa}$ south of $12^{\circ} \mathrm{N}$. These changes in the zonal winds are qualitatively consistent with those of Chen et al. (2010). The factor-separation analysis indicates that the radiative interaction with aerosols (the AR effect; Fig. 13b) is primarily responsible for the enhancement of the easterlies between $11^{\circ}-22^{\circ} \mathrm{N}$ and $700-500 \mathrm{hPa}$ and weakening of the easterly flow below $800 \mathrm{hPa}$. The AR effect also slightly reduces the strength of the jet north of $22^{\circ} \mathrm{N}$, weakens the upper-level easterlies south of $12^{\circ} \mathrm{N}$, and strengthens the upper-level westerlies between $15^{\circ}$ and $20^{\circ} \mathrm{N}$. The AM interactions (Fig. 13a) result in much weaker changes in the strength of the easterly jet, compared to AR, and lead to primarily positive changes above $700 \mathrm{hPa}$ between $12^{\circ}$ and $24^{\circ} \mathrm{N}$. Note that the total AMR impact is not just the sum of the two individual effects (AM and AR), whose sum in the upper troposphere would result in much larger negative changes between $12^{\circ}$ and $14^{\circ} \mathrm{N}$ and smaller negative changes between $18^{\circ}$ and $24^{\circ} \mathrm{N}$. The pattern of the overall zonal 

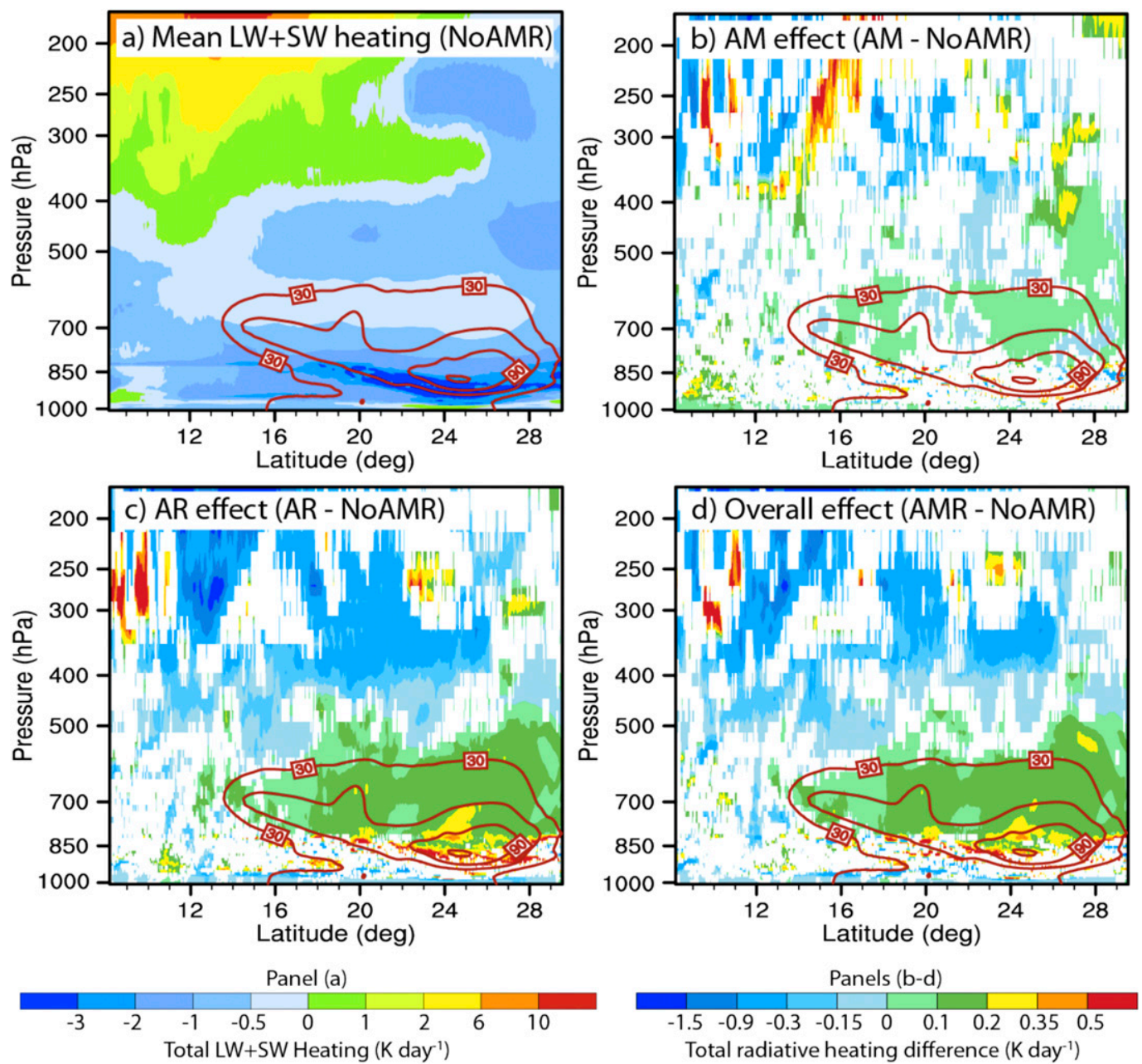

FIG. 10. (a) Vertical cross sections of zonal-mean total radiative (longwave and shortwave) heating $\left(\mathrm{K} \mathrm{day}^{-1}\right)$ from the NoAMR simulation averaged over the 2-day period 24-25 Aug. Color scale at lower left. (b)-(d) The impact of dust aerosols on zonal-mean total radiative heating rate $\left(\mathrm{K} \mathrm{day}^{-1}\right)$, with the impact measured as the difference between each simulation (AM, AR, and AMR) and the NoAMR simulation. Color scale for (b)-(d) at lower right. The white space indicates where the impact is statistically insignificant at the $99 \%$ confidence level. Red contours indicate zonal-mean total dust mixing ratios at $30 \mu \mathrm{g} \mathrm{m}^{-3}$ intervals from the NoAMR simulation.

wind changes is qualitatively similar to that found in coarser grid simulations by Bretl et al. (2015) and suggests a small southward shift of the AEJ position. These findings contrast with Wilcox et al. (2010) and Reale et al. (2011), who found northward shifts of the AEJ associated with dust.

The dust and other aerosols generally have a smaller impact on the meridional flow than zonal wind through most of the troposphere (Figs. 13d-f). Microphysical effects of the dust (AM; Fig. 13d) are generally small throughout the domain, while the radiative impacts (AR; Fig. 13e) lead to a relatively larger change. As a result, the combined AMR results (Fig. 13f) are similar to AR and act to slightly weaken the northerly flow below and southerly flow near the top of the dust layer.
The presence of the dust and other aerosols changes the vertical motion within the SAL and beyond, as shown in Figs. 13g-i. The changes from the NoAMR case are highly variable, with larger areas where the changes are not statistically significant. The largest changes occur in the ITCZ region. Microphysical impacts (Fig. 13g) lead to nearly offsetting positive and negative differences in the ITCZ, resulting in a small net change in vertical motion. In AR (Fig. 13h), a more consistent behavior is seen below $300 \mathrm{hPa}$, with a larger reduction in rising motion within a narrow band near $12^{\circ}-13^{\circ} \mathrm{N}$ in the northern part of the ITCZ and offsetting positive and negative differences south of $\sim 11^{\circ} \mathrm{N}$. The combined effect seen in AMR (Fig. 13i) is a small southward shift of the rising motion in the ITCZ and a net reduction in 

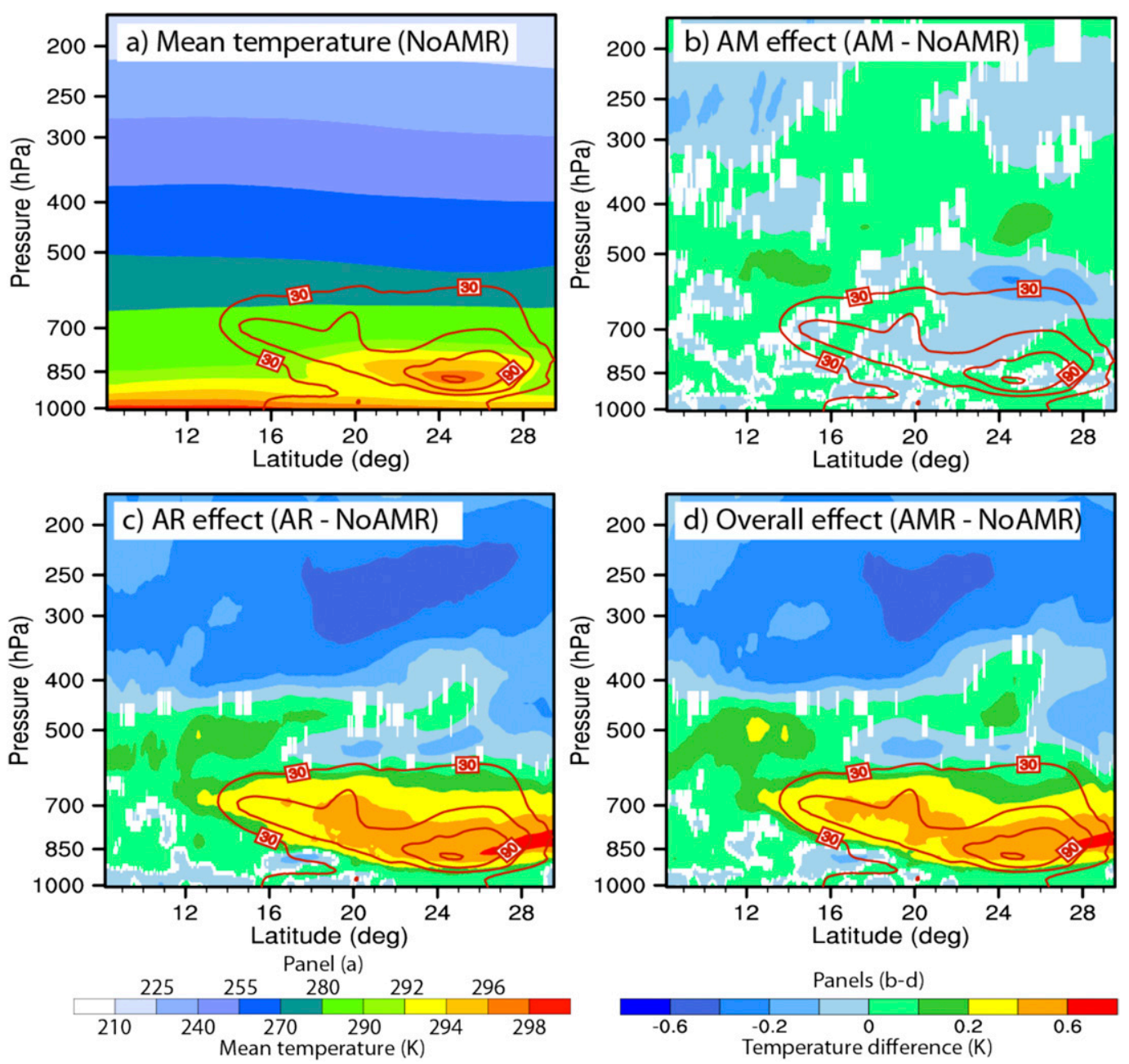

FIG. 11. As in Fig. 10, but for zonal-mean temperature.

upward motion in the region below $300 \mathrm{hPa}$. However, an enhancement of upward motion in the ITCZ above $300 \mathrm{hPa}$ is present and is consistent with the idea of delayed growth of rain and enhanced convection aloft $(\mathrm{Li}$ and Min 2010). Within the dust layer, the pattern of vertical motion (rising to the north, sinking to the south; Fig. 12c) is enhanced by both the AM and AR effects, although the AR effect is stronger. When viewed in combination with the changes in meridional air motions, the radiative effects of dust tend to produce two vertical circulations: a shallow one within the dust layer [upward (downward) motion changes on the northern (southern) ends of the dust layer and southerly (northerly) changes at the bottom (top) of the dust layer] and a deeper one outside of the dust layer (generally upward motion changes above the southern portion of the dust layer and downward changes in the ITCZ). The deeper circulation change qualitatively matches that described by Karyampudi and Carlson (1988).

\section{3) WATER VAPOR AND CLOUD/PRECIPITATION HYDROMETEOR}

Having characterized the microphysical and radiative impacts of dust on the zonal-mean vertical motions, we can now examine and explain the dust impacts on moisture and cloud and precipitation hydrometeor fields. Aerosols are expected to impact cloud and precipitation distributions, either directly through the production of $\mathrm{CCN}$ and IN or indirectly through the modification of atmospheric circulation (i.e., vertical motions) caused by radiative interactions with dusty and/or cloudy air. To provide a baseline for an assessment of the impacts of dust on cloud and precipitation hydrometeors, Fig. 14a shows the zonal-mean total cloud (liquid and ice) and precipitation (rain, snow, and graupel) hydrometeor fields. The liquid phase is dominated by cloud water, including within precipitating regions of the ITCZ. Precipitation is largely absent in the low-level cloud deck 

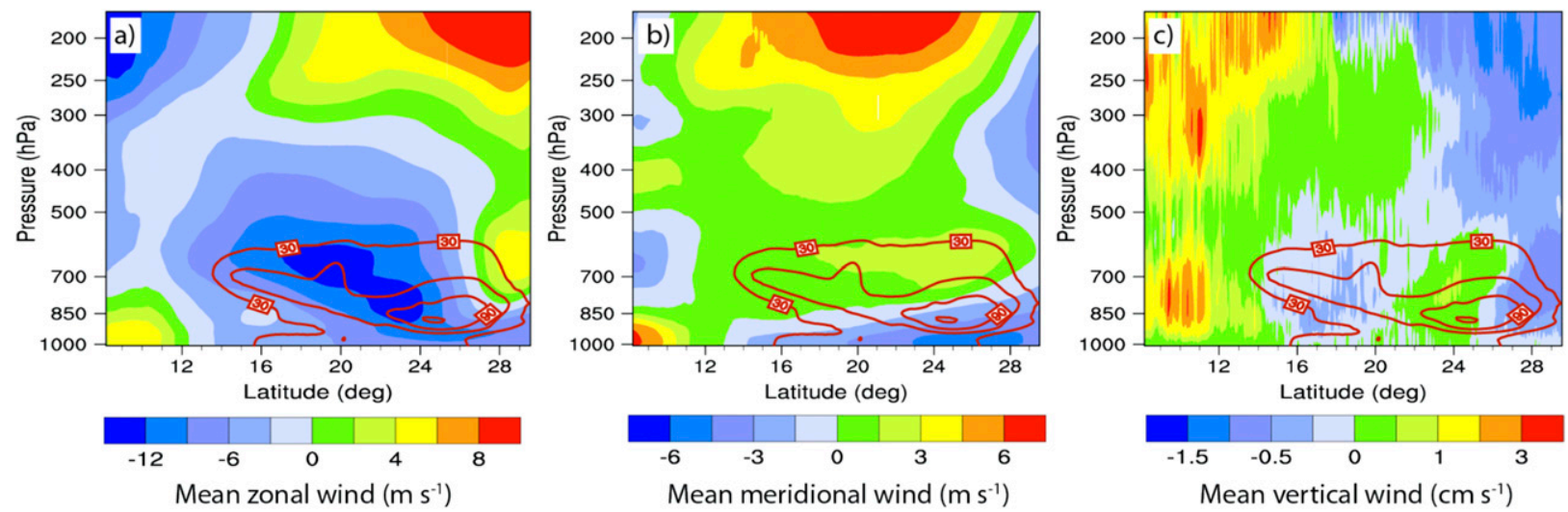

FIG. 12. Vertical profiles of zonal-mean (a) zonal wind $\left(\mathrm{m} \mathrm{s}^{-1}\right)$, (b) meridional wind $\left(\mathrm{m} \mathrm{s}^{-1}\right)$, and (c) vertical wind ( $\left.\mathrm{cm} \mathrm{s}^{-1}\right)$ from NoAMR averaged over 24-25 Aug.

north of $16^{\circ} \mathrm{N}$, which is generally confined to below $850 \mathrm{hPa}$ beneath the SAL. As the base of the dust layer rises to the south, so too does the depth of the hydrometeors, with deep convection occurring south of $\sim 12^{\circ} \mathrm{N}$ in the ITCZ. The ice phase is dominated by precipitation between $\sim 600$ and $300 \mathrm{hPa}$ and by cloud ice above $\sim 250 \mathrm{hPa}$ (not shown). Tropical anvils, on average, extend to $25^{\circ} \mathrm{N}$ as the ice is carried northward by uppertropospheric southerlies (Fig. 12b).

As with the impacts of dust on vertical motions, and unlike with other fields such as temperature and horizontal winds, the microphysical (Fig. 14b) and radiative (Fig. 14c) impacts of the dust on the hydrometeor fields are comparable in magnitude and distribution. In general, where the changes in vertical motions are positive, cloud and precipitation hydrometeors increase, and where the changes are negative, hydrometeor values decrease; however, at upper levels, horizontal transport is also a factor in the hydrometeor changes in the AR and AMR simulations, as weaker southerly flow between $8^{\circ}$ and $16^{\circ} \mathrm{N}$ results in lower hydrometeor transport from the ITCZ. The microphysics coupling (Fig. 14b) leads to a reduction of cloud and precipitation between $12^{\circ}$ and $14^{\circ} \mathrm{N}$, with cloud and precipitation enhancement dominating between $10^{\circ}$ and $11^{\circ} \mathrm{N}$. The AM effects also result in a small increase in hydrometeors just above the SAL north of $\sim 18^{\circ} \mathrm{N}$. When only radiative interactions with the dust and other aerosols are included (Fig. 14c), the pattern of the hydrometeorproduction change within the ITCZ and the SAL is similar to that resulting from the AM effect, but with larger overall decreases within the northward-extending anvil region at midlevels $(500-300 \mathrm{hPa})$. Liquid water in the low-level cloud deck below $850 \mathrm{hPa}$ is highly variable and tends to suggest a shift of water mass to lower levels. The overall impact on hydrometeor fields (Fig. 14d) appears to be heavily affected by both AM and AR.
However, the AR effect dominates the change in liquid water below $850 \mathrm{hPa}$ to the north of $18^{\circ} \mathrm{N}$.

Changes in specific (Figs. 15a-c) and relative humidity (Figs. 15d-f) are generally of the same sign; that is, $\mathrm{RH}$ increases (decreases) where specific humidity increases (decreases). The AR effect generally dominates the AM effect and largely determines the overall effect. Consistent with the pattern of vertical motion changes within the dust layer (Figs. 13g-i), specific humidity increases in the rising motion and decreases in the subsiding motion in the northern and southern parts, respectively, of the dust layer. Above the southern portion of the dust layer and within the ITCZ, specific humidity decreases above $\sim 600 \mathrm{hPa}$ due to reduced upward motion and reduced evaporation (sublimation) of anvil water (ice) associated with reduced hydrometeor values. Relative humidity changes are consistent with those of specific humidity, except that drying is enhanced by radiative warming of the dust layer. This result is consistent with the finding by Chen et al. (2010) that the radiative impact of dust lowers the RH within the lowest part of the SAL.

\section{4) WIND SHEAR}

Vertical wind shear plays a role in tropical cyclogenesis and intensification, and it has been hypothesized that the SAL can act to enhance vertical wind shear near tropical waves and storms (Dunion and Velden 2004; Evan et al. 2006; Sun et al. 2009). While vertical shear is often characterized by the change in winds between two specific levels, such as 850 and $200 \mathrm{hPa}$, here we examined profiles of the vertical shear of the wind $\sqrt{(\partial U / \partial z)^{2}+(\partial V / \partial z)^{2}}$, where $U$ is the zonal wind, $V$ is the meridional wind, and $z$ is the layer thickness between each model level. Figure 16a indicates that the strongest zonal-mean vertical shear $\left(>6 \times 10^{-3} \mathrm{~s}^{-1}\right)$ is near the top of or within the boundary layer from $8^{\circ}$ to $11^{\circ} \mathrm{N}$ and $26^{\circ}$ to $30^{\circ} \mathrm{N}$, with high shear 

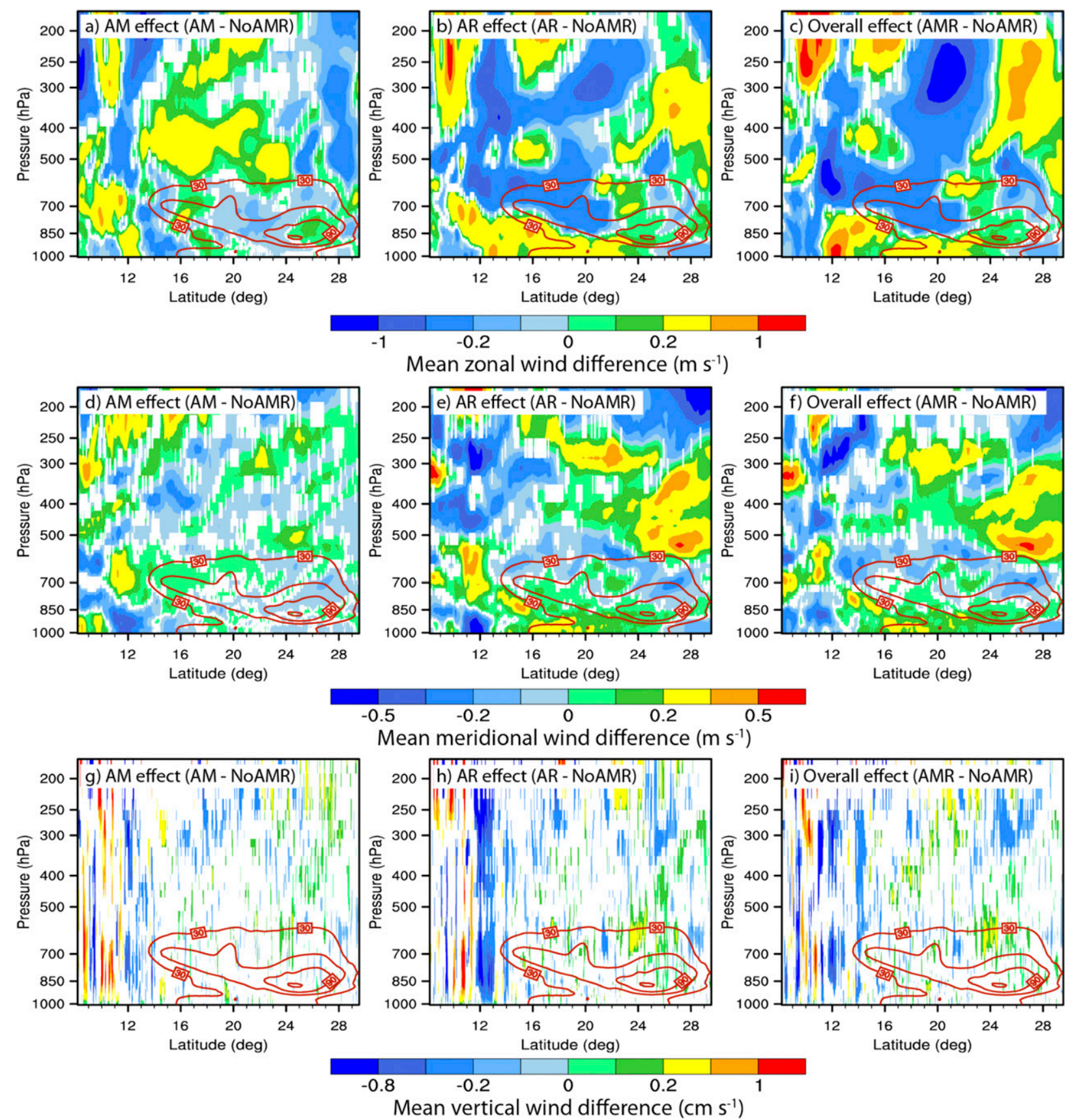

FIG. 13. As in Figs. 10b-d, but for zonal-mean (a)-(c) zonal wind $\left(\mathrm{m} \mathrm{s}^{-1}\right),(\mathrm{d})-(\mathrm{f})$ meridional wind $\left(\mathrm{m} \mathrm{s}^{-1}\right)$, and (g)-(i) vertical wind (cm s $\left.{ }^{-1}\right)$.

values also along the base of the dust layer. A layer of weak shear $\left(<2 \times 10^{-3} \mathrm{~s}^{-1}\right)$ occurs between 700 and $600 \mathrm{hPa}$ at almost all latitudes in the domain. Enhanced shear is also found above $600 \mathrm{hPa}$ and north of $16^{\circ} \mathrm{N}$ between the AEJ and the upper-level westerlies. A very deep layer of weak shear occurs between the ITCZ and the AEJ between $\sim 11^{\circ}$ and $15^{\circ} \mathrm{N}$. The largest overall impact (Fig. 16d) of the dust and other aerosols is to increase the vertical shear in the region of weaker shear to the south of the AEJ near $700 \mathrm{hPa}$. The vertical shear also increases through much of the dust layer, except at low levels on the north side, and also just above the dust layer up to about $500 \mathrm{hPa}$. This increase in shear at lower and midlevels is mainly driven by the radiative (AR; Fig. 16c) effects of the dust and other aerosols. The changes in shear agree well with the simulation results of Chen et al. (2010), who claim that the AR 

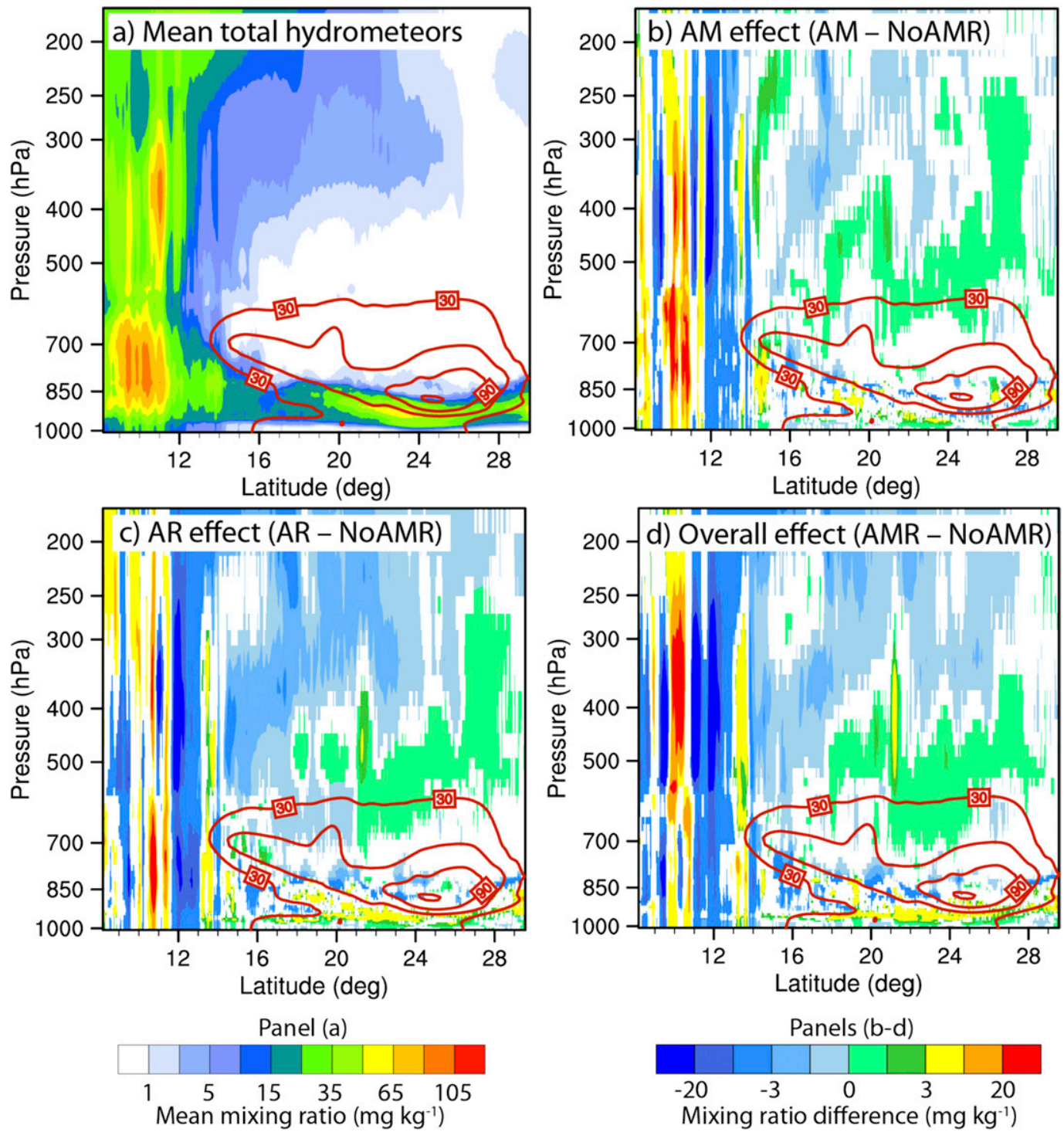

FIG. 14. As in Fig. 10, but for total cloud and precipitation hydrometeor mixing ratio.

effect tends to enhance the vertical shear of the zonal wind between 750 and $550 \mathrm{hPa}$. The increase in shear south of the AEJ can potentially create less favorable conditions for cyclogenesis, although whether the increase in shear would be sufficient to suppress development would depend on the strength of the shear and, likely, on the characteristics (strength, depth, and size) of the vortex (Rappin and Nolan 2012; Zhou 2015).

\section{Conclusions}

A Saharan air layer (SAL) outbreak during 24-25 August 2013 was sampled during the HS3 campaign by the NASA Global Hawk aircraft equipped with a dropsonde system and cloud lidar. The aircraft observations characterized the vertical structure of the SAL and its near environment along four north-south flight legs centered on a nondeveloping tropical wave. The SAL contained a deep layer of dust embedded in the AEJ to the north of the wave center (defined in a wave-following reference frame) and a more vertically narrow, sloping (increasing height from north to south) zone of dust within wave-relative westerly flow to the south of the vortex center. The SAL air mass exhibited characteristics frequently observed in previous studies (Carlson and Prospero 1972; Carlson 1979; Karyampudi and Carlson 1988; Parker et al. 2005; Messager et al. 2010; Braun 2010), including very warm and dry conditions within the lower portion of the SAL, colder and moister conditions near the top, and low static stability within the SAL. Very 

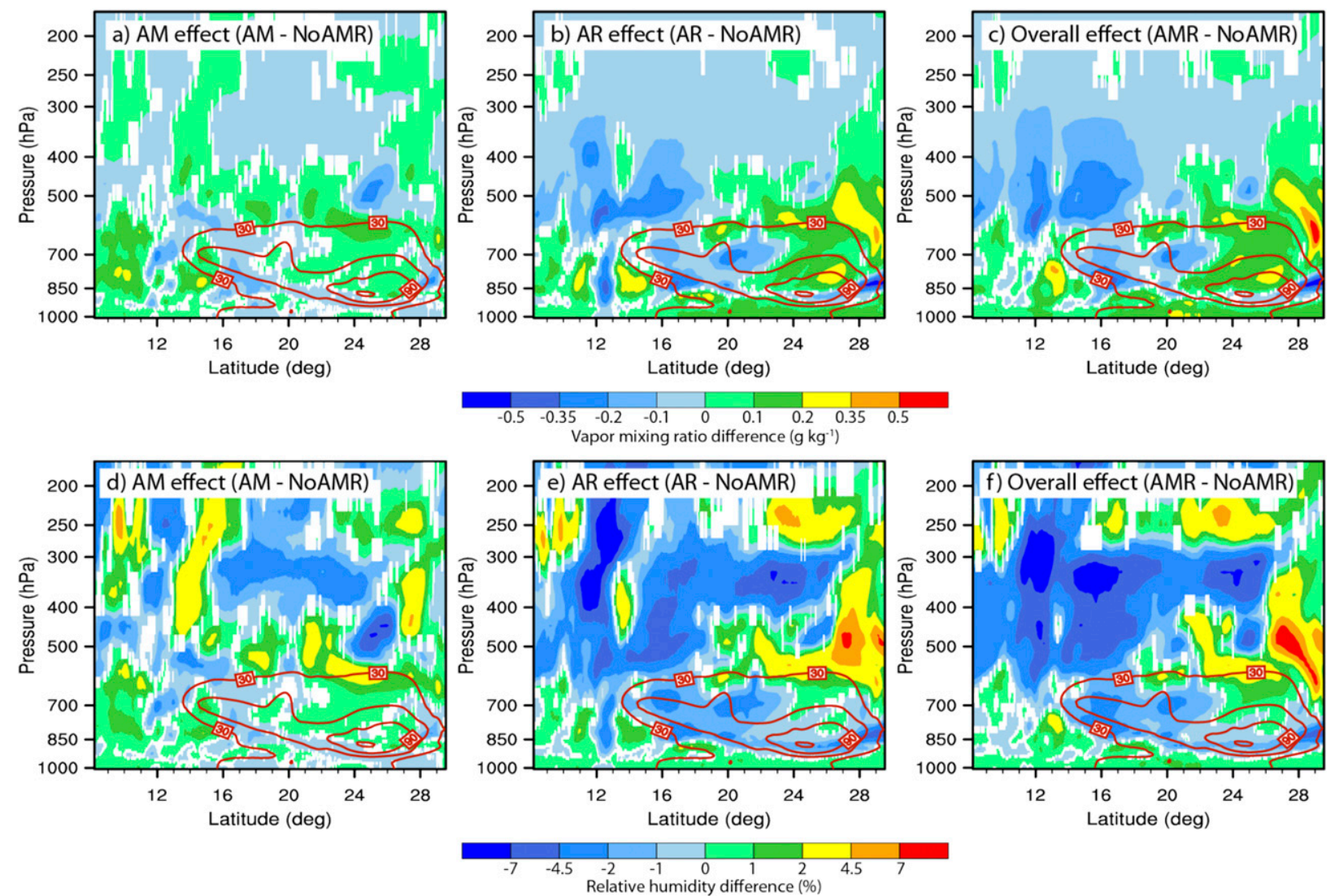

FIG. 15. As in Figs. 10b-d, but for zonal-mean (a)-(c) specific humidity $\left(\mathrm{g} \mathrm{kg}^{-1}\right)$ and (d)-(f) RH (\%).

high stability marked the base of the SAL and extended several hundred kilometers south of the vortex center, thereby suppressing deep convection within the wave.

To understand better the impact of Saharan dust and other aerosols on the thermodynamic conditions within the SAL and impacts on the near environment, we used the NU-WRF Model with interactive aerosol-microphysicsradiation processes and employed a factor-separation method. Four different simulations were conducted: a fully coupled run including aerosol-microphysical-radiation (AMR) effects, runs with aerosol-microphysics (AM) or aerosol-radiation (AR) effects only, and a control run with no explicit aerosol effects (NoAMR). NUWRF reasonably captured the evolution of major features of this SAL event. The model simulated the distribution of dust well, although the simulated AOD was up to $50 \%$ lower than MODIS observations and about 18\% lower than ground-based AERONET observations at Cape Verde. The G-SDSU instrument simulator included in NU-WRF was used to calculate the cloud and aerosol attenuated total backscatter at $1064 \mathrm{~nm}$, and the results were compared to the CPL measurements. NU-WRF reproduced the CPL-observed structure of the dust layer, including the tapering of the thickness of the dust plume from $\sim 5 \mathrm{~km}$ near $22^{\circ} \mathrm{N}$ to $3.3 \mathrm{~km}$ near the center of the wave's vortex (viewed in terms of the wave-relative flow) at $17^{\circ} \mathrm{N}$. South of the wave center, a vertically narrow region of dust sloped upward toward the south to $3.8-\mathrm{km}$ altitude. The simulation also reproduced the cloud layer at the top of the boundary layer below the SAL. Consistent with the AOD simulation, NU-WRF underestimated the backscatter in comparison with the CPL measurements. NU-WRF profiles of temperature, $\mathrm{RH}$, wind speed, and wind direction, matched in space and time, were in good agreement with dropsonde observations, including within the SAL layer $(\sim 850-500 \mathrm{hPa})$.

A factor-separation method was applied to the simulations to examine the impacts of AMR interactions, as well as AM and AR interactions, on SAL structure and the surrounding environment. The presence of dust aerosols directly and indirectly changed atmospheric radiative heating profiles within and above the SAL. The direct effect of the aerosols (AR) led to weak warming of the dust layer, with the strongest warming near the base of the layer. Dust-induced changes in vertical motions and cloud/precipitation hydrometeors in the ITCZ and tropical anvils generally caused decreased radiative heating or increased cooling above 

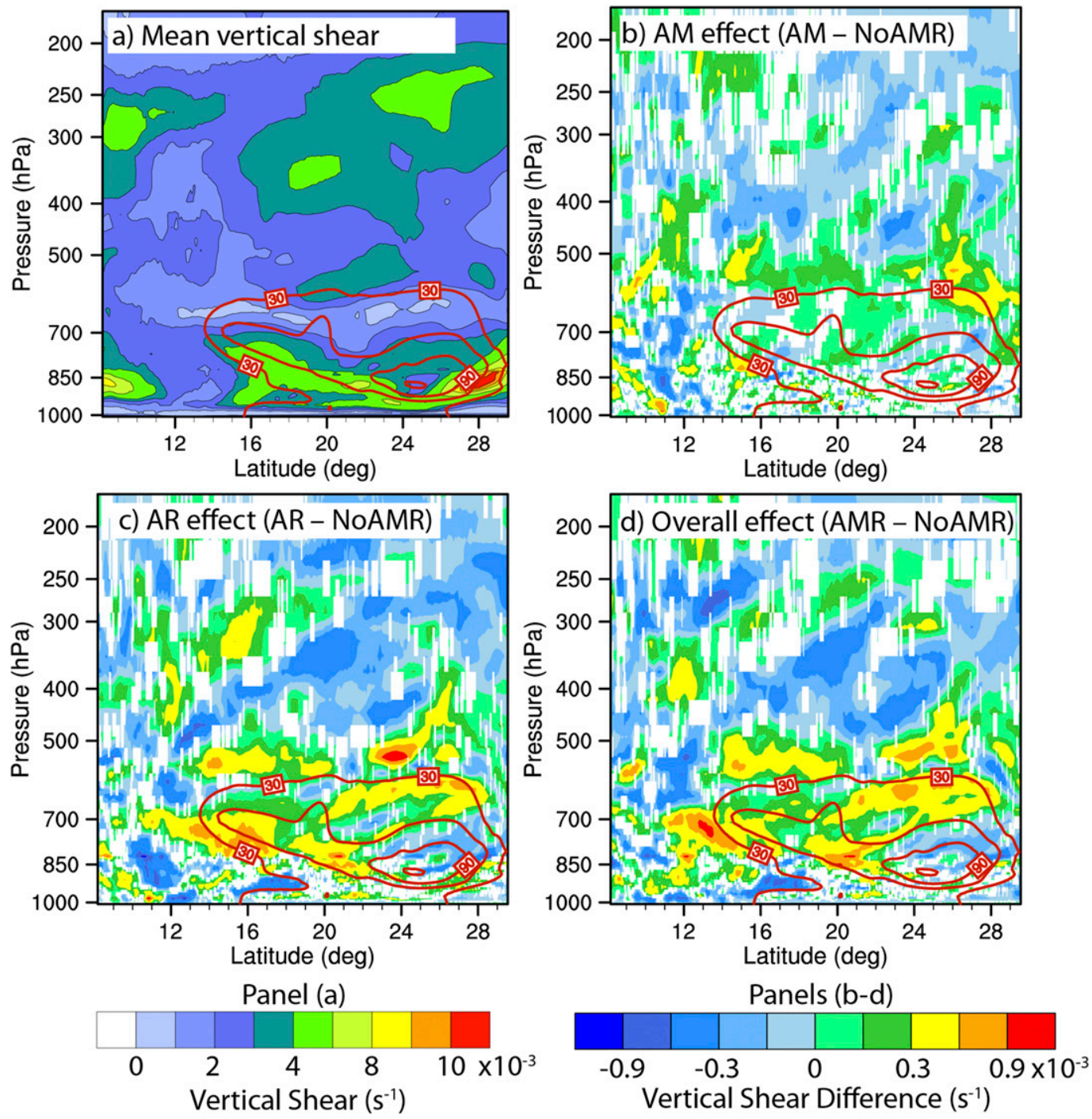

FIG. 16. As in Fig. 10, but for zonal-mean vertical shear of the wind.

$500 \mathrm{hPa}$, with AR-induced cooling dominating north of $11^{\circ} \mathrm{N}$

Temperature changes caused by Saharan dust included warming below $450 \mathrm{hPa}$ and cooling above this level. The strongest warming of more than $0.6 \mathrm{~K}$ was near the bottom of the SAL layer, which acted to maintain the temperature inversion at the base of the SAL in the presence of net radiative cooling. The AR effect dominated the overall temperature change, with the temperature change pattern similar to that in Chen et al. (2010).

Changes in the moisture and cloud/precipitation hydrometeor fields can be understood in large measure in the context of the dust-induced changes in vertical motion. The zonal-mean vertical motion pattern is characterized by two circulation patterns. On larger scales, the Hadley circulation produces rising motion in the ITCZ and sinking motions north of about $22^{\circ}-24^{\circ} \mathrm{N}$. Embedded within the dust layer within this Hadley circulation is a thermally direct overturning circulation with rising motion in the northern portion of the dust layer (where dust concentrations are greatest and temperatures are warmest) and descending motions within the southern portion of the dust layer. This pattern within the dust layer is accentuated by the radiative effects and, to a lesser extent, the microphysical effects of dust, leading to increases (decreases) in specific humidity in the northern (southern) portions of the dust layer. Above and to the south of the dust layer, both the microphysical and radiative impacts of dust tend to counter the vertical motions associated with the Hadley circulation so that specific humidity and midlevel clouds 
increase above the dust layer north of $\sim 20^{\circ} \mathrm{N}$ and decrease south of $20^{\circ} \mathrm{N}$. Relative humidity distributions are similar to those for specific humidity, with the exception of the lower portion of the dust layer, which shows drier conditions where the relative drying effects of warming tend to outweigh the effects of increases in specific humidity. Within the ITCZ, microphysical and radiative impacts tend to produce a slight southward shift of the rising motion and hydrometeors, and in the overall effect a net decrease in vertical motions and hydrometeors, particularly right at the southern edge of the dust layer. The weaker ITCZ results in reduced hydrometeors in the northward-extending anvil clouds, which then leads to cloud-radiative feedbacks at upper levels.

The AMR interactions strengthened the AEJ by about $1.0 \mathrm{~m} \mathrm{~s}^{-1}$ at the southern edge of the jet (near $12^{\circ} \mathrm{N}$, about $7^{\circ}$ latitude south of the AEJ wind maximum located near $19^{\circ} \mathrm{N}$ ) between 500 and $700 \mathrm{hPa}$ and weakened the jet by up to $0.5 \mathrm{~m} \mathrm{~s}^{-1}$ north of the jet axis, with contributions coming from both AM and AR effects. Beneath the SAL, the overall AMR effect was to reduce the easterly flow primarily due to the AR effect, while AR effects and, to a lesser extent, AM effects weakened the tropical upper-level easterlies above $300 \mathrm{hPa}$ in the ITCZ. Meridional wind changes were typically much weaker than for zonal winds, with AR effects again dominant. The changes in the zonal winds caused increases in vertical wind shear within much of the dust layer, as well as up to $100 \mathrm{hPa}$ above it. The vertical shear also increased up to $3^{\circ}$ latitude to the south of the southern edge of the dust layer and about $6^{\circ}-8^{\circ}$ to the south of the AEJ axis.

For the weak AEW studied here, cyclogenesis was clearly not possible as the dusty, dry, and warm SAL air was transported around the southern side of the region of maximum vorticity by the wave-relative zonal flow. Dust-radiative impacts created unfavorable conditions for development by maintaining the high stability above the boundary layer, increasing drying in the southern portion of the dust layer (the portion wrapping around the southern side of the vorticity maximum), and increasing vertical wind shear at low to midlevels. The applicability of these results to AEWs that have at least some potential for tropical cyclogenesis is unclear. Developing systems tend to form south of the dust layer (Karyampudi and Carlson 1988; Braun 2010; Bretl et al. 2015), where the thermodynamic characteristics of the SAL tend to favor rising motion (Karyampudi and Carlson 1988; Braun 2010) and enhance convection. However, the radiative and microphysical effects of the dust tend to counter the rising motion in the ITCZ and increase wind shear, and whether these dust impacts are of sufficient magnitude to prevent cyclogenesis may depend greatly on the dust loading in the SAL and the characteristics of the AEW and proto vortex. Therefore, additional studies of systems with high potential for cyclogenesis, but with significant dust interactions, remain necessary.

Acknowledgments. This research was funded by the HS3 investigation, which was funded by NASA's Earth Venture Suborbital program at NASA Headquarters. This research was also partially funded by the NASA's Modeling, Analysis, and Prediction (MAP) program (Solicitation NNH12ZDA001N-MAP). The authors thank two anonymous reviewers for their very helpful comments and the NASA Center for Climate Simulation (NCCS) for supercomputing and mass storage support. Thanks are also due to the NASA AERONET and MODIS teams for their aerosol optical depth data.

\section{REFERENCES}

Barkan, J., H. Kutiel, P. Alpert, and P. Kishcha, 2004: Synoptics of dust intrusion days from the African continent into the Atlantic Ocean. J. Geophys. Res., 109, D08201, https://doi.org/ 10.1029/2003JD004416.

Ben-Ami, Y., I. Koren, and O. Altaratz, 2009: Patterns of North African dust transport over the Atlantic: Winter vs. summer, based on CALIPSO first year data. Atmos. Chem. Phys., 9, 7867-7875, https://doi.org/10.5194/acp-9-7867-2009.

Braun, S. A., 2010: Reevaluating the role of the Saharan air layer in Atlantic tropical cyclogenesis and evolution. Mon. Wea. Rev., 138, 2007-2037, https://doi.org/10.1175/2009MWR3135.1.

_ P. A. Newman, and G. M. Heymsfield, 2016: NASA's Hurricane and Severe Storm Sentinel (HS3) investigation. Bull. Amer. Meteor. Soc., 97, 2085-2102, https://doi.org/10.1175/ BAMS-D-15-00186.1.

Bretl, S., P. Reutter, C. C. Raible, S. Ferrachat, C. Schnadt Poberaj, L. E. Revell, and U. Lohmann, 2015: The influence of absorbed solar radiation by Saharan dust on hurricane genesis. J. Geophys. Res. Atmos., 120, 1902-1917, https://doi.org/ 10.1002/2014JD022441.

Carlson, T. N., 1979: Atmospheric turbidity in Saharan dust outbreaks as determined by analyses of satellite brightness data. Mon. Wea. Rev., 107, 322-335, https://doi.org/10.1175/1520-0493(1979)107<0322: ATISDO $>2.0 . \mathrm{CO} ; 2$.

- and J. M. Prospero, 1972: The large-scale movement of Saharan air outbreaks over the northern equatorial Atlantic. J. Appl. Meteor., 11, 283-297, https://doi.org/10.1175/1520-0450(1972) $011<0283$ :TLSMOS $>2.0$.CO;2.

— haran dust. J. Atmos. Sci., 37, 193-213, https://doi.org/10.1175/ 1520-0469(1980)037<0193:RHRFSD>2.0.CO;2.

Chen, S.-H., S.-H. Wang, and M. Waylonis, 2010: Modification of Saharan air layer and environmental shear over the eastern Atlantic Ocean by dust-radiation effects. J. Geophys. Res., 115, D21202, https://doi.org/10.1029/2010JD014158.

_ Y.-C. Liu, T. R. Nathan, C. Davis, R. Torn, N. Sowa, C.-T. Cheng, and J.-P. Chen, 2015: Modeling the effects of dustradiative forcing on the movement of Hurricane Helene (2006). Quart. J. Roy. Meteor. Soc., 141, 2563-2570, https:// doi.org/10.1002/qj.2542. 
Chin, M., and Coauthors, 2002: Tropospheric aerosol optical thickness from the GOCART model and comparisons with satellite and sun photometer measurements. J. Atmos. Sci., 59, 461-483, https:// doi.org/10.1175/1520-0469(2002)059<0461:TAOTFT >2.0.CO;2.

- T. Diehl, P. Ginoux, and W. Malm, 2007: Intercontinental transport of pollution and dust aerosols: Implications for regional air quality. Atmos. Chem. Phys., 7, 5501-5517, https:// doi.org/10.5194/acp-7-5501-2007.

Chou, M.-D., and M. J. Suarez, 1999: A solar radiation parameterization (CLIRAD-SW) for atmospheric studies. NASA Tech. Rep. NASA/TM-1999-10460, 38 pp.

Cook, K. H., 1999: Generation of the African easterly jet and its role in determining West African precipitation. J. Climate, 12, 1165-1184, https://doi.org/10.1175/1520-0442(1999)012<1165: GOTAEJ $>2.0 . \mathrm{CO} ; 2$.

Dee, D. P., and Coauthors, 2011: The ERA-Interim reanalysis: Configuration and performance of the data assimilation system. Quart. J. Roy. Meteor. Soc., 137, 553-597, https://doi.org/10.1002/qi.828.

DeMott, P. J., and Coauthors, 2010: Predicting global atmospheric ice nuclei distributions and their impacts on climate. Proc. Natl. Acad. Sci. USA, 107, 11217-11222, https://doi.org/ 10.1073/pnas.0910818107.

Dunion, J. P., 2011: Rewriting the climatology of the tropical North Atlantic and Caribbean Sea atmosphere. J. Climate, 24, 893908, https://doi.org/10.1175/2010JCLI3496.1.

—_, and C. S. Velden, 2004: The impact of the Saharan air layer on Atlantic tropical cyclone activity. Bull. Amer. Meteor. Soc., 85, 353-366, https://doi.org/10.1175/BAMS-85-3-353.

— tropical sounding based on awareness of the Saharan air layer: Results from 2002. J. Climate, 21, 5242-5253, https://doi.org/ 10.1175/2008JCLI1868.1

Evan, A. T., J. Dunion, J. A. Foley, A. K. Heidinger, and C. S. Velden, 2006: New evidence for a relationship between Atlantic tropical cyclone activity and African dust outbreaks. Geophys. Res. Lett., 33, L19813, https://doi.org/10.1029/ 2006GL026408.

Freitas, S. R., and Coauthors, 2007: Including the sub-grid scale plume rise of vegetation fires in low resolution atmospheric transport models. Atmos. Chem. Phys., 7, 3385-3398, https:// doi.org/10.5194/acp-7-3385-2007.

Ginoux, P., M. Chin, I. Tegen, J. Prospero, B. Holben, O. Dubovik, and S.-J. Lin, 2001: Sources and distributions of dust aerosols simulated with the GOCART model. J. Geophys. Res., 106, 20 255-20 273, https://doi.org/10.1029/2000JD000053.

Gong, S. L., 2003: A parameterization of sea-salt aerosol source function for sub- and super-micron particles. Global Biogeochem. Cycles, 17, 1097, https://doi.org/10.1029/ 2003 GB002079.

Guenther, A., T. Karl, P. Harley, C. Wiedinmyer, P. I. Palmer, and C. Geron, 2006: Estimates of global terrestrial isoprene emissions using MEGAN (Model of Emissions of Gases and Aerosols from Nature). Atmos. Chem. Phys., 6, 3181-3210, https://doi.org/ 10.5194/acp-6-3181-2006.

Hock, T. F., and J. L. Franklin, 1999: The NCAR GPS dropwindsonde. Bull. Amer. Meteor. Soc., 80, 407-420, https://doi.org/ 10.1175/1520-0477(1999)080<0407:TNGD>2.0.CO;2.

Holben, B. N., and Coauthors, 1998: AERONET-A federated instrument network and data archive for aerosol characterization. Remote Sens. Environ., 66, 1-16, https://doi.org/ 10.1016/S0034-4257(98)00031-5.

Ismail, S., and Coauthors, 2010: LASE measurements of water vapor, aerosol, and cloud distributions in Saharan air layers and tropical disturbances. J. Atmos. Sci., 67, 1026-1047, https://doi.org/10.1175/2009JAS3136.1.

Karyampudi, V. M., and T. N. Carlson, 1988: Analysis and numerical simulations of the Saharan air layer and its effect on easterly wave disturbances. J. Atmos. Sci., 45, 3102-3136, https://doi.org/ 10.1175/1520-0469(1988)045<3102:AANSOT>2.0.CO;2.

— , and Coauthors, 1999: Validation of the Saharan dust plume conceptual model using lidar, Meteosat, and ECMWF data Bull. Amer. Meteor. Soc., 80, 1045-1076, https://doi.org/ 10.1175/1520-0477(1999)080<1045:VOTSDP > 2.0.CO;2.

Kaufman, Y. J., D. Tanré, L. A. Remer, E. F. Vermote, A. Chu, and B. N. Holben, 1997: Operational remote sensing of tropospheric aerosol over land from EOS moderate resolution imaging spectroradiometer. J. Geophys. Res., 102, 17 051-17 067, https:// doi.org/10.1029/96JD03988.

Khain, A., N. BenMoshe, and A. Pokrovsky, 2008: Factors determining the impact of aerosols on surface precipitation from clouds: An attempt at classification. J. Atmos. Sci., 65, 17211748, https://doi.org/10.1175/2007JAS2515.1.

Koehler, K. A., S. M. Kreidenweis, P. J. DeMott, A. J. Prenni, C. M. Carrico, B. Ervens, and G. Feingold, 2006: Water activity and activation diameters from hygroscopicity data-Part II: Application to organic species. Atmos. Chem. Phys., 6, 795-809, https:// doi.org/10.5194/acp-6-795-2006.

Lang, S. E., W.-K. Tao, X. Zeng, and Y. Li, 2011: Reducing the biases in simulated radar reflectivities from a bulk microphysics scheme: Tropical convective systems. J. Atmos. Sci. 68, 2306-2320, https://doi.org/10.1175/JAS-D-10-05000.1.

Levy, R. C., S. Mattoo, L. A. Munchak, L. A. Remer, A. M. Sayer, F. Patadia, and N. C. Hsu, 2013: The Collection 6 MODIS aerosol products over land and ocean. Atmos. Meas. Tech., 6, 2989-3034, https://doi.org/10.5194/amt-6-2989-2013.

Li, R., and Q.-L. Min, 2010: Impacts of mineral dust on the vertical structure of precipitation. J. Geophys. Res., 115, D09203, https://doi.org/10.1029/2009JD011925.

Liu, Y., and P. H. Daum, 2004: Parameterization of the autoconversion process. Part I: Analytical formulation of the Kessler-type parameterizations. J. Atmos. Sci., 61, 1539-1548, https://doi.org/ 10.1175/1520-0469(2004)061<1539:POTAPI >2.0.CO;2.

Ma, P.-L., K. Zhang, J. J. Shi, T. Matsui, and A. Arking, 2012: Direct radiative effect of mineral dust on the development of African easterly waves in late summer, 2003-07. J. Appl. Meteor. Climatol., 51, 2090-2104, https://doi.org/10.1175/ JAMC-D-11-0215.1.

Matsui, T., and Coauthors, 2013: GPM satellite simulator over ground validation sites. Bull. Amer. Meteor. Soc., 94, 1653 1660, https://doi.org/10.1175/BAMS-D-12-00160.1.

_ , and Coauthors, 2014: Introducing multisensor satellite radiance-based evaluation for regional Earth system modeling. J. Geophys. Res. Atmos., 119, 8450-8475, https://doi.org/ 10.1002/2013JD021424.

McGill, M., and D. Hlavka, 2015: Hurricane and Severe Storm Sentinel (HS3) Global Hawk Cloud Physics Lidar (CPL) [ATB files]. NASA Global Hydrology Resource Center DAAC, http://doi.org/10.5067/HS3/CPL/DATA202.

Messager, C., D. J. Parker, O. Reitebuch, A. Agustí-Panareda, C. M. Taylor, and J. Cuesta, 2010: Structure and dynamics of the Saharan atmospheric boundary layer during the West African monsoon onset: Observations and analyses from the research flights of 14 and 17 July 2006. Quart. J. Roy. Meteor. Soc., 136, 107-124, https://doi.org/10.1002/qj.469.

Min, Q.-L., R. Li, B. Lin, E. Joseph, S. Wang, Y. Hu, V. Morris, and F. Chang, 2009: Evidence of mineral dust altering cloud 
microphysics and precipitation. Atmos. Chem. Phys., 9, 3223 3231, https://doi.org/10.5194/acp-9-3223-2009.

Nalli, N. R., and Coauthors, 2005: Profile observations of the Saharan air layer during AEROSE 2004. Geophys. Res. Lett., 32 , L05815, https://doi.org/10.1029/2004GL022028.

Ott, S.-T., A. Ott, D. W. Martin, and J. A. Young, 1991: Analysis of a trans-Atlantic Saharan dust outbreak based on satellite and GATE data. Mon. Wea. Rev., 119, 1832-1850, https://doi. org/10.1175/1520-0493(1991)119<1832:AOATAS >2.0.CO;2.

Parker, D. J., C. D. Thorncroft, R. R. Burton, and A. DiongueNiang, 2005: Analysis of the African easterly jet, using aircraft observations from the JET2000 experiment. Quart. J. Roy. Meteor. Soc., 131, 1461-1482, https://doi.org/10.1256/qj.03.189.

Peters-Lidard, C. D., and Coauthors, 2015: Integrated modeling of aerosol, cloud, precipitation and land processes at satelliteresolved scales. Environ. Modell. Software, 67, 149-159, https://doi.org/10.1016/j.envsoft.2015.01.007.

Prospero, J. M., and T. N. Carlson, 1970: Radon-222 in the North Atlantic trade winds: Its relationship to dust transport from Africa. Science, 167, 974-977, https://doi.org/10.1126/science.167.3920.974. _, and _ 1972: Vertical and areal distribution of Saharan dust over the western equatorial North Atlantic Ocean. J. Geophys. Res., 77, 5255-5265, https://doi.org/10.1029/JC077i027p05255.

_- E. Bonatti, C. Schubert, and T. N. Carlson, 1970: Dust in the Caribbean atmosphere traced to an African dust storm. Earth Planet. Sci. Lett., 9, 287-293, https://doi.org/10.1016/ 0012-821X(70)90039-7.

Rappin, E. D., and D. S. Nolan, 2012: The effect of vertical shear orientation on tropical cyclogenesis. Quart. J. Roy. Meteor. Soc., 138, 1035-1054, https://doi.org/10.1002/qj.977.

Reale, O., K. Lau, and A. da Silva, 2011: Impact of interactive aerosol on the African easterly jet in the NASA GEOS-5 global forecasting system. Wea. Forecasting, 26, 504-519, https://doi.org/10.1175/WAF-D-10-05025.1.

Remer, L. A., and Coauthors, 2005: The MODIS aerosol algorithm, products, and validation. J. Atmos. Sci., 62, 947-973, https://doi.org/10.1175/JAS3385.1.

Rosenfeld, D., U. Lohmann, G. B. Raga, C. D. O’Dowd, M. Kulmala, S. Fuzzi, A. Reissell, and M. O. Andreae, 2008: Flood or drought: How do aerosols affect precipitation? Science, 321, 1309-1313, https://doi.org/10.1126/science.1160606.

Sessions, W. R., H. E. Fuelberg, R. A. Kahn, and D. M. Winker, 2011: An investigation of methods for injecting emissions from boreal wildfires using WRF-Chem during ARCTAS. Atmos. Chem. Phys., 11, 5719-5744, https://doi.org/10.5194/acp-11-5719-2011.

Shi, J. J., and Coauthors, 2014: Implementation of an aerosol-cloud microphysics-radiation coupling into the NASA Unified WRF: Simulation results for the 6-7 August 2006 AMMA special observing period. Quart. J. Roy. Meteor. Soc., 140, 2158-2175, https://doi.org/10.1002/qj.2286.

Stein, U., and P. Alpert, 1993: Factor separation in numerical simulations. J. Atmos. Sci., 50, 2107-2115, https://doi.org/ 10.1175/1520-0469(1993)050<2107:FSINS > 2.0.CO;2.

Sun, D., W. K. M. Lau, M. Kafatos, Z. Boybeyi, G. Leptoukh, C. Yang, and R. Yang, 2009: Numerical simulations of the impacts of the Saharan air layer on Atlantic tropical cyclone development. J. Climate, 22, 6230-6250, https://doi.org/10.1175/2009JCLI2738.1.

Tao, W.-K., and Coauthors, 2003: Microphysics, radiation and surface processes in the Goddard Cumulus Ensemble (GEC) model. Meteor. Atmos. Phys., 82, 97-137, https://doi.org/ 10.1007/s00703-001-0594-7.

, X. Li, A. Khain, T. Matsui, S. Lang, and J. Simpson, 2007: Role of atmospheric aerosol concentration on deep convective precipitation: Cloud-resolving model simulations, J. Geophys. Res., 112, D24S18, https://doi.org/10.1029/2007JD008728.

$\longrightarrow$, J. J. Shi, S. S. Chen, S. Lang, P.-L. Lin, S.-Y. Hong, C. PetersLidard, and A. Hou, 2011: The impact of microphysical schemes on hurricane intensity and track. Asia-Pac. J. Atmos. Sci., 47, 1-16, https://doi.org/10.1007/s13143-011-1001-z.

Tao, Z., S. M. Larson, D. J. Wuebbles, A. Williams, and M. Caughey, 2003: A summer simulation of biogenic contributions to groundlevel ozone over the continental United States. J. Geophys. Res., 108, 4404, https://doi.org/10.1029/2002JD002945.

_- J. A. Santanello, M. Chin, S. Zhou, Q. Tan, E. M. Kemp, and C. D. Peters-Lidard, 2013: Effect of land cover on atmospheric processes and air quality over the continental United States-A NASA Unified WRF (NU-WRF) Model study. Atmos. Chem. Phys., 13, 6207-6226, https://doi.org/ 10.5194/acp-13-6207-2013.

, H. Yu, and M. Chin, 2015: The role of aerosol-cloudradiation interactions in regional air quality-A NU-WRF study over the United States. Atmosphere, 6, 1045-1068, https://doi.org/10.3390/atmos6081045.

, — - and — 2016: Impact of transpacific aerosol on air quality over the United States: A perspective from aerosolcloud-radiation interactions. Atmos. Environ., 125, 48-60, https://doi.org/10.1016/j.atmosenv.2015.10.083.

Thorncroft, C. D., and B. J. Hoskins, 1994: An idealized study of African easterly waves. I: A linear view. Quart. J. Roy. Meteor. Soc., 120, 953-982, https://doi.org/10.1002/qj.49712051809.

Twohy, C. H., 2015: Measurements of Saharan dust in convective clouds over the tropical eastern Atlantic Ocean. J. Atmos. Sci., 72, 75-81, https://doi.org/10.1175/JAS-D-14-0133.1.

- and Coauthors, 2009: Saharan dust particles nucleate droplets in eastern Atlantic clouds. Geophys. Res. Lett., 36, L01807, https://doi.org/10.1029/2008GL035846.

Wick, G., 2015: Hurricane and Severe Storm Sentinel (HS3) Global Hawk AVAPS Dropsonde System. NASA Global Hydrology Resource Center DAAC, https://doi.org/10.5065/ D6736P31.

Wiedinmyer, C., S. K. Akagi, R. J. Yokelson, L. K. Emmons, J. A. Al-Saadi, J. J. Orlando, and A. J. Soja, 2011: The Fire Inventory from NCAR (FINN): A high resolution global model to estimate the emissions from open burning. Geosci. Model Dev., 4, 625-641, https://doi.org/10.5194/gmd-4-625-2011.

Wilcox, E. M., K. Lau, and K.-M. Kim, 2010: A northward shift of the North Atlantic Ocean intertropical convergence zone in response to summertime Saharan dust outbreaks. Geophys. Res. Lett., 37, L04804, https://doi.org/10.1029/ 2009 GL041774.

Zhou, W., 2015: The impact of vertical shear on the sensitivity of tropical cyclogenesis to environmental rotation and thermodynamic state. J. Adv. Model. Earth Syst., 7, 1872-1884, https:// doi.org/10.1002/2015MS000543.

Zipser, E. J., and Coauthors, 2009: The Saharan air layer and the fate of African easterly waves-NASA's AMMA field study of tropical cyclogenesis. Bull. Amer. Meteor. Soc., 90, 11371156, https://doi.org/10.1175/2009BAMS2728.1. 